\title{
Linking Pensions to Life Expectancy: Tackling Conceptual Uncertainty through Bayesian Model Averaging
}

\author{
Jorge M. Bravo ${ }^{1, *, t, \ddagger(\mathbb{D}) \text { and Mercedes Ayuso }}{ }^{2, \ddagger(\mathbb{D}}$ \\ 1 NOVA IMS Universidade Nova de Lisboa, MagIC, Université Paris-Dauphine PSL, CEFAGE-UE, \\ 1070 Lisbon, Portugal \\ 2 Department of Econometrics, Statistics and Applied Economy, Riskcenter-UB, University of Barcelona, \\ 08034 Barcelona, Spain; mayuso@ub.edu \\ * Correspondence: jbravo@novaims.unl.pt \\ + Current address: Universidade Nova de Lisboa (NOVA IMS), Campus de Campolide, 1070 Lisboa, Portugal. \\ $\ddagger$ These authors contributed equally to this work.
}

Citation: Bravo, J.M.; Ayuso, M. Linking Pensions to Life Expectancy: Tackling Conceptual Uncertainty through Bayesian Model Averaging. Mathematics 2021, 9, 3307. https:// doi.org/10.3390/math9243307

Academic Editors: Joseba Iñaki De la Peña Esteban, Asier Garayeta and María del Carmen Valls Martínez

Received: 19 November 2021 Accepted: 17 December 2021 Published: 19 December 2021

Publisher's Note: MDPI stays neutral with regard to jurisdictional claims in published maps and institutional affiliations.

Copyright: () 2021 by the authors. Licensee MDPI, Basel, Switzerland. This article is an open access article distributed under the terms and conditions of the Creative Commons Attribution (CC BY) license (https:// creativecommons.org/licenses/by/ $4.0 /)$.

\begin{abstract}
Linking pensions to longevity developments at retirement age has been one of the most common policy responses of pension schemes to aging populations. The introduction of automatic stabilizers is primarily motivated by cost containment objectives, but there are other dimensions of welfare restructuring in the politics of pension reforms, including recalibration, rationalization, and blame avoidance for unpopular policies that involve retrenchments. This paper examines the policy designs and implications of linking entry pensions to life expectancy developments through sustainability factors or life expectancy coefficients in Finland, Portugal, and Spain. To address conceptual and specification uncertainty in policymaking, we propose and apply a Bayesian model averaging approach to stochastic mortality modeling and life expectancy computation. The results show that: (i) sustainability factors will generate substantial pension entitlement reductions in the three countries analyzed; (ii) the magnitude of the pension losses depends on the factor design; (iii) to offset pension cuts and safeguard pension adequacy, individuals will have to prolong their working lives significantly; (iv) factor designs considering cohort longevity markers would have generated higher pension cuts in countries with increasing life expectancy gap.
\end{abstract}

Keywords: sustainability factor; retirement age; Bayesian model averaging; pensions; life expectancy; mortality forecasting; redistribution; policymaking under uncertainty

JEL Classification: H55; G22; C63; C53; H23

\section{Introduction}

High-income countries have been responding to continuous longevity increases, below replacement-fertility levels, upward trends in old age dependency ratios, low productivity gains and economic growth, rapidly shifting labor markets, declining financial market returns with systemic risks, e.g., a switch towards non-financial defined contribution (NDC) schemes in Sweden, Italy, Poland, Latvia, and Norway; pension financialization, i.e., the expansion of private complementary occupational and personal pre-funded definedcontribution (DC) pensions, and/or gradual parametric public pension reforms (e.g., updates in early and normal retirement ages, modifications in the defined benefit (DB) pension formula), as part of their efforts to reduce or eliminate short-term and long-term imbalances between revenues and expenditures, alleviating the pressure on public finances, together with efforts to preserve minimum pension adequacy $[1,2]$.

Recently, in EU countries subject to economic and financial bailout programs (Greece, Portugal, Ireland, Cyprus), pension reforms represented one of the most visible faces of the influence of supranational organizations ("Troika") on the retrenchments and welfare state reforms. In other cases, for instance, in Spain, reforming pensions is one of the 
conditions required to have access to the Recovery and Resilience Facility (RRF), set up by the European Union to support post-COVID 19 reforms and investments undertaken by the member states. The fiscal impact of population aging extends beyond pension schemes, competing with healthcare and long-term care for public funding, and has been aggravated by the consequences of the COVID 19 pandemic. The 2007/2008 global financial market crisis and the subsequent shift towards a "low-for-long" interest rate scenario altered the setting for the expansion of pre-funded private pensions.

For national public pension schemes, one common denominator in most reforms involves automatic adjustment or stabilization mechanisms, specifically designed to correct the financial imbalance of the pension system, mechanically updating the scheme's parameters to demographic and/or economic developments. For instance, these mechanisms decide in advance how the system will adjust to restore financial solvency if an increase in the old age dependency ratio (e.g., Germany), a decline in the workforce (e.g., Japan), an increase in life expectancy at retirement age (e.g., Denmark, the Netherlands, Portugal, Finland, Cyprus, UK), a decline in wages (e.g., Germany) is observed, or if the system is projected to go into a long-term deficit (e.g., Sweden, Canada, U.S., Spain). Variations of other automatic stabilizers have been elements of many pension systems for decades. For instance, wage, real GDP, productivity, and CPI price indexation of the earnings tax base and/or benefit payments are now basic features of most earnings-related old age pension schemes.

Automatic pension stabilizers differ in several important design aspects [3,4]: (i) in the triggering event (e.g., life expectancy change, the balance ratio value); (ii) in the alternative stages of pensions at which the correction can occur: accumulation, annuitization, and decumulation; (iii) in whether the triggering event generates an automatic update (e.g., indexation of pension benefits) or just a recommendation for policy action; (iv) in the updated parameter (e.g., normal retirement age, indexation rate, social contribution rate, initial pension); (v) in the certainty (actual) or projected (forecasted) nature of the triggering event; (vi) in the ex-ante or ex-post nature of the adjustment; (vii) in the frequency of revision; and (viii) in specific design features (e.g., indexation lags).

Automatic pension stabilizers modify the redistribution of costs and benefits within and across generations (e.g., between current and future pensioners, between the lifetime rich and the lifetime poor) and alter the way risk is shared within and across generations, for instance, by changing the way individual and aggregate longevity risk is pooled among plan participants, by transferring interest rates and investment risks to retirees [5]. They also change the nature of the pension promise being offered to younger workers and represent a paradigm shift in the responsibility for old age income, in what some authors name the (risk) privatization and marketization (commodification) of pension policy [6].

Although the objective of introducing automatic stabilizers is primarily to minimize the impact of economic and/or demographic shocks on the financing of pension schemes (cost containment), in the politics of pension reforms, there are other dimensions of welfare restructuring. This includes an implicit goal of introducing economic and actuarial rationality for substantiating the prescribed changes (recalibration and/or rationalization), adapting to changing norms and demands and to new conceptions about achieving consolidated goals, circumventing the political risks of regular negotiations between social partners to approve unpopular reforms that involve retrenchments [7]. Typically, governments tend to procrastinate and postpone the adoption of pension reforms because of the political costs they carry and the opposition of social partners and/or of organized interest groups. The introduction of automatic stabilizers replaces regular discretionary measures, contributing to enhancing the credibility of the system, of social trust, and the support of the intergenerational contract by preventing otherwise unexpected public finance crises and major benefit cuts in the future. To elude blame for unpopular policies, policymakers often recourse to compensation and obfuscation strategies including, for instance, sequencing, long-phasing in periods, and the adoption of long indexation lags [8]. 
A recent and expanding trend in most pension reforms adopted in developed countries has been to automatically link pension benefits to life expectancy developments observed at retirement age. The link has been established and reinforced in multiple ways [9-14]: (i) linking entry pensions to sustainability factors or life expectancy coefficients (Finland, Portugal, Spain (as defined in the 2013 pension, now abandoned)) to old age dependency ratios (Germany, Japan), or to life annuity coefficients (Sweden, Italy, Poland, Latvia, Norway); (ii) automatically indexing normal and early retirement ages to life expectancy markers (e.g., Denmark, the Netherlands, Portugal, UK, Slovakia, Italy, Finland, Greece); (iii) making the eligibility requirements contingent to the contribution length (e.g., France, Italy); (iv) conditioning the annual pension indexation (the Netherlands, Luxembourg); (v) conditioning the pension penalties (bonuses) for early (late) retirement to the contribution length (e.g., Portugal); (vi) introducing insurance and non-insurance risk-sharing annuity products with partial or no guarantees (e.g., the Netherlands, the United States); (vii) determining the accumulation of pension entitlements (the Netherlands); (viii) phasing in national Financial Defined Contribution (FDC) plans (e.g., Chile).

Introducing sustainability factors and/or life annuity coefficients linking initial pension benefits to life expectancy developments at retirement ages in DB systems was one of the first policy responses of public pension schemes to the long-term solvency challenges posed by population aging. Defined contribution schemes incorporate a mechanism that automatically adjusts the initial benefit level to changes in life expectancy at the time of annuitizing the accumulated (financial or notional) wealth. The introduction of sustainability factors incorporates this DC feature into DB schemes. In addition, this policy contributes to establishing a pseudo-actuarial structure tightening the link between contributions and benefits in aggregate terms, strengthening the incentives for prolonging working lives, and enhancing active labor force participation (recommodification). This is also important for rational retirement timing decisions and formal labor market participation. Linking pensions to longevity is seen as leading to the restructuring and modernization of the social contract while retaining the old age social insurance nature of the scheme that pools individual longevity risk among birth cohorts and across generations.

For a given retirement age, sustainability factors reduce the initial (and the lifetime) pension benefits to counterbalance the extra costs of longer retirement periods that follow from increased life expectancy prospects. This is often justified as providing for intergenerational fairness, although normally in a very approximate way. From the point of view of pension adequacy, sustainability factors gradually reduce the relationship between benefits and pre-retirement labor market earnings - the replacement rate-which is often perceived as a measure of the generosity of social protection systems, raising old age poverty concerns among pensioners in the most disadvantaged groups. This correction has been combined in some countries (e.g., Portugal) with flexible retirement age approaches, offering workers the possibility to: (i) retire at the same age as previous generations, but with a reduced pension, or (ii) extend the working life for as long as necessary to offset pension cuts. Linking pensions to life expectancy increases the uncertainty about retirement income and the length of life after retirement, which are critical parameters in retirement (consumption, saving, labor market) planning, with possible effects on subjective well-being.

The way pensions have been linked to life expectancy, suffers, however, from several weaknesses. First, except for Italy, total population (unisex) life expectancy measures computed from national statistical office (NSO) period life tables have been used to index sustainability factors (and retirement ages) to longevity developments. It is well-known that period life expectancy disregards expected longevity improvements, underestimating the remaining lifetime [15-17]. Recent empirical studies have shown that the life expectancy gap-the difference between the period and cohort life expectancy measures—at retirement age is systematic, sizable, and continues to increase, generating unintended and important ex-ante tax/subsidies from future to current generations, creating an unfair actuarial link between the contribution effort and pension entitlements, distorting labor market decisions, delaying pension reforms [18]. 
The use of period instead of birth cohort measures is often justified by the lack of cohort life expectancy estimates at most NSOs, and by the fact that period life expectancy is a very imprecise but objective (i.e., based on actual data and not on forecasted data, not subject thus to statistical uncertainty) measure of the remaining lifetime at retirement, whereas cohort life expectancy relies (at least partially) on mortality forecasts. Pension (social) policy design and analysis combine assumptions and data to draw conclusions. The use of stronger (implausible) assumptions sacrifices the policy's credibility (Manski, 2011). The use of period instead of birth cohort longevity measures reveals, however, one of the most common ways to deal with uncertainty about the future in social and economic policymaking, which is denying uncertainty, due to the increasing complexity in the systems, due to their expanding interactions with other systems, and due to the uncertainty in the development of exogenous factors [19].

Second, the design of sustainability factors is uniform across socioeconomic groups, neglecting increasing empirical evidence showing sizable and increasing socioeconomic gradients in life expectancy and high lifespan inequality at retirement, which makes pension schemes more regressive, redistributing pension wealth from short to long-lived individuals [20-22]. Lifespan inequality has been classified as the "mother" of all inequalities, an ultimate manifestation of health and living conditions disparities [23]. Third, in many countries, life expectancy trends are not followed by parallel movements in healthy life expectancy (HLE) and disability-free life expectancy (DFLE), challenging the executability of pension reforms targeting longer working lives and questioning again its redistributive effects.

Against this background, this paper examines the policy design and provides comparable cross-country forecasts of the sustainability factors introduced in the national public pension schemes of selected countries-Finland, Portugal, and Spain-to automatically index old age (and disability in some cases) entry pensions to life expectancy developments at retirement ages. The three countries pursued alternative pension policy designs and are, thus, good laboratories for social policy analyses and discussions, including, in the case of Spain, assessing the consequences of reform retrenchments. We estimate the impact of sustainability factors on pension benefits, quantify the size of the resulting pension cuts and estimate the extra working (and contribution) years required to compensate for its effect in the DB formula and to get a full pension. We discuss the challenges and the feasibility of policy approaches seeking an extension of working lives in increasingly disruptive labor markets, in which diverse non-standard forms of employment are more frequent. We assess to what extent the use of a period instead of a cohort approach to life expectancy and life annuity computation affects the sustainability factor policy outcomes and discuss the implications of denying uncertainty in pension policy against the alternative of using robust forecasting approaches, possibly combined with ex-post correction mechanisms.

To generate sustainability factor forecasts, life expectancy and/or annuity coefficients must be estimated from stochastic mortality models. Model selection and model combination are currently the two competing approaches in mortality modeling and forecasting in multiple domains. The standard approach to age-specific mortality rate forecasting is to pursue a "winner-take-all" perspective by which, for each population, a single believed to be the «best» or «true» model is selected from a set of candidate approaches using some method or statistical criteria (e.g., Bayesian information criterion, cross-validation, forecasting accuracy metric, bootstrapping, stepwise regression, shrinkage methods). Statistical inference proceeds conditionally upon the assumption that the "best" model actually generated the data, neglecting model uncertainty (conceptual uncertainty). Stated differently, statistical inference can only be relied upon if the selected model happens to be a good approximation to the data generating process. If the model fails to capture other aspects of reality, inference tends to be misleading (systematically wrong or overly precise) and underrepresented.

To forecast age-specific mortality rates, the demographic, financial, and actuarial literature proposes a growing number of single- and multi-population discrete-time and 
continuous-time age-period-cohort stochastic mortality models, principal component methods, and smoothing approaches (see, e.g., [24-41] and references therein). The use of different look back periods, different selection procedures, alternative accuracy metrics, misspecification problems, and the presence of structural breaks in the data generating process can lead to different model choices and time series forecasts.

The empirical work in economics, finance, and social modeling is subject to a large amount of uncertainty about the model specification. This may be the consequence of [42]: (i) theory uncertainty, i.e., the lack of a universally accepted theory that has been empirically verified as a (near) perfect explanation of reality; (ii) specification uncertainty, i.e., the different ways in which theories can be implemented in empirical models (e.g., different ways of measuring theoretical concepts, alternative functional forms, parametric vs. semior nonparametric specifications, choice of covariates, lag-lengths), and (iii) heterogeneity uncertainty and independence of the observables. Within economics and social policymaking, conceptual uncertainty is critical since at least three broad and important categories of questions are not related to specific models: (i) identifying the factors or determinants driving economic processes or social dynamics; (ii) policy evaluation; and (iii) prediction. Because of that, Bayesian model combinations have been proposed to improve forecasting accuracy and address model uncertainty in longevity modeling [18,43-45].

To tackle the conceptual uncertainty problem in social policymaking that prevents countries from using cohort life expectancy measures in pension policy, to cope with the need to generate comparable cross-country estimates, and to overcome the limitations of some traditional methods, this paper follows [18] and uses a dynamic Bayesian model averaging (BMA) or ensemble (BME) of nine heterogeneous stochastic mortality models to forecast survivorship. The set of models comprises generalized age-period-cohort (GAPC) stochastic mortality models, principal component methods, and smoothing approaches. The estimation procedure involves, first, the identification of the model confidence set-the subset of superior models-taking each model's out-of-sample forecasting performance in the validation period and a fixed-rule trimming scheme. The BMA approach assumes that the model confidence set includes the true data generating process. Second, we compute posterior probabilities (model weights) based on each method forecasting accuracy in the test set. Third, the method combines the individual model predictions into a composite forecast. Finally, Bayesian prediction intervals considering stochastic process, model, and parameter risks are derived using the model-averaged tail area (MATA) approach [46]. Model combination aims at finding a composite model that better approximates the actual data generation process and its multiple sources of uncertainty. The approach has a long tradition in the statistical and forecasting literature, but it still gives its first steps in policymaking studies.

The empirical results show that: (i) the unisex period and cohort life expectancy measures of the remaining lifetime at retirement ages in Finland, Portugal, and Spain are forecasted to increase significantly in the next decades; (ii) the impact of sustainability factors on pension entitlements is substantial and will continue to increase, particularly in the case of Portugal that, among the three countries analyzed, has the more severe policy design considering the year 2000 as the base year (since the 2013 reform) without the mitigating effect of the time value of money (discount or interest rate effect) as in the Finnish factor design; (iii) to compensate for the sustainability factor effect, workers will have to prolong their working (and contribution) lives significantly in the future to get a full pension; (iv) the use of cohort instead of period life expectancy markers in policy design would have generated slightly higher pension cuts in the future, particularly in countries in which the life expectancy gap at retirement ages is projected to increase. These empirical results have important micro and macroeconomic implications for the design of pension schemes, for individual life cycle labor market, consumption and saving decisions, and for policymaking under uncertainty.

The remainder of this article is structured as follows: Section 2 summarizes the key materials and methods used in the paper. Section 3 presents the results for the projected 
sustainability factors for the three countries, together with forecasts of the period and cohort life expectancy estimates at the reference retirement ages and of the additional working years required to get a full pension if sustainability factors are not adopted. Section 4 critically discusses the results and concludes. The technical details are relegated to the Appendix A.

\section{Materials and Methods}

\subsection{Life Expectancy and Life Annuity Measures}

Let $T_{x}(t)$ denote the random variable expressing the number of years an individual aged $x$ at time $t$ is expected to live [47]. Consider the time interval (age range) [0, $\omega]$, with $\omega$ the finite maximum age of the life table. Consider the filtered probability space $(\Omega, \mathbb{F}, \mathbb{P})$, large enough to support the dynamics of the stochastic force of mortality (instantaneous rate of mortality) at a certain age $x$ measured in year $t, \mu_{x}(t)$, and the stochastic discounting (nonnegative) interest rate process $\left\{r_{t}: t \geq 0\right\}$. Let $\mathcal{F}_{t}:=\mathcal{M}_{t} \vee \mathcal{D}_{t}=\sigma\left(\mathcal{M}_{t} \cup \mathcal{D}_{t}\right)$ represent the joint filtration generated by the discounting interest rate and the life expectancy, with $\mathcal{D}_{t}$ the filtration resulting from the dynamics of the discounting interest rate up to time $t$, and $\mathcal{M}_{t}$ the filtration corresponding to the dynamics of $\mu_{x}$ up to time $t$.

However, because mortality and life table data are only observed periodically (usually annually), assumptions must be made regarding the discretized stochastic process. In this paper, we assume that $\mu_{x}(t)$ is constant within each square in a Lexis diagram, i.e., $\mu_{x+\xi}(t+\epsilon)=\mu_{x}(t)$ for any $0 \leq \xi, \epsilon<1$. This assumptions allows us to approximate $\mu_{x}(t)$ using the central death rate $m_{x}(t)$, computed from observed data (deaths, $D_{x, t}$, and corresponding exposure-to-risk, $E_{x, t}$, classified by age at death, year of death, and birth cohort). From $m_{x}(t)$ estimates, one-year survival probabilities are computed using the exponential distribution $p_{x}(t)=\exp \left(-m_{x}(t)\right)$.

The $\tau=T-t$ year survival function can be written as:

$$
{ }_{\tau} p_{x}(t):=E\left[\exp \left(-\int_{0}^{\tau} \mu_{x+s}(s) d s\right) \mid \mathcal{M}_{t}\right],
$$

or as:

$$
{ }_{\tau} p_{x}(t):=E\left[\prod_{s=0}^{\tau-1}\left[1-q_{x+s}(t+s)\right] \mid \mathcal{M}_{t}\right] .
$$

Given the stochastic force of mortality process, the period life expectancy at age $x$ in year $t$ is computed as:

$$
\dot{e}_{x}^{P}(t):=\int_{0}^{\omega-x}{ }_{s} p_{x}(t) d s
$$

Period life expectancy measures implicitly assume that mortality rates observed in a single year (or in a small number of consecutive years) will remain constant throughout the remainder of a given individual's life, i.e., they neglect expected longevity improvements. This contrasts with cohort life expectancy measures, which estimate the expected remaining lifetime of a birth cohort aged $x$ in year $t$ accounting for expected mortality developments by combining observed longitudinal data and forecasting methods. Formally, the cohort life expectancy at age $x$ in year $t, \dot{e}_{x}^{C}(t)$, is computed as:

$$
\dot{e}_{x}^{C}(t):=\int_{0}^{\omega-x} s p_{x}(t+s) d s
$$

The systematic difference between the period and cohort life expectancy measures at a given age and calendar year-the concept of life expectancy gap $\dot{e}_{x}^{\text {Gap }}(t)$-is computed as [16]: $\dot{e}_{x}^{\text {Gap }}(t):=\dot{e}_{x}^{C}(t)-\dot{e}_{x}^{P}(t)$. Under certain mild assumptions, the life expectancy gap has a welfare economic interpretation representing a ex-ante tax/subsidy $S_{x}(t)$ from future to current pensioners equal to: 


$$
S_{x}(t):=\frac{\dot{e}_{x}^{G a p}(t)}{\dot{e}_{x}^{P}(t)} \times 100,
$$

with positive (negative) values representing a tax (subsidy) rate to future pensioners.

Without loss of generality, consider an immediate life annuity contract paying one monetary unit to an individual aged $x$ at time $t$ with remaining lifetime $T_{x}(t)=\omega-x$. The $\mathcal{F}_{t}$-measurable best estimate of the fair value (single premium) of this contract is

$$
a_{x}(t):=\sum_{s=1}^{\omega-x} E^{\mathbb{Q}}\left[{ }_{s} p_{x}(t) \cdot D F(t, t+s) \mid \mathcal{F}_{t}\right],
$$

where $\mathbb{Q}$ is the risk-neutral measure and $D F(t, T)$ is a stochastic exponential discount factor defined as

$$
D F(t, T):=\exp \left(-\int_{t}^{T} r_{u} d u\right) .
$$

\subsection{Linking Pension Benefits to Life Expectancy through Sustainability Factors}

This section summarizes the sustainability (longevity, life expectancy) factor designs adopted in the national public pension schemes of selected countries-Finland, Portugal, Spain - to automatically link initial pension benefits to life expectancy developments. Finland was the first country to introduce a sustainability factor as part of an extensive and systemic pension reform adopted in 2005, harmonizing the benefit rules of different earnings-related schemes, tightening the actuarial link between earned income and pension entitlements, introducing flexibility in the retirement age timing (people can choose to retire fully or partially at any age above the lower limit age, now following a stepwise increase until it reaches age 65 in 2027), establishing a progressive accrual rate scheme increasing with age and computing the pensionable wage on the whole contribution career. In Finland, since 2010, the pay-as-you-go (PAYG) DB benefit formula adjusts the earnings-related entry pension to increased longevity by multiplying the accrued pensionable wage by a life expectancy coefficient, $S F^{F I N}(t)$, equal to the quotient between the annuity due factor computed at the reference age of $62(x=62)$ in the base year $2009\left(t_{0}=2009\right), \ddot{a}_{x}\left(t_{0}\right)$, and the factor computed at the same age in the year when the insured reaches the set retirement age, $\ddot{a}_{x}(t)$, i.e.,

$$
S F^{F I N}(t):=\frac{\ddot{a}_{x}\left(t_{0}\right)}{\ddot{a}_{x}(t)}
$$

with $\ddot{a}_{x}(t)$ computed as follows

$$
\ddot{a}_{x}(t):=\sum_{s=0}^{\omega-x} E^{\mathbb{Q}}\left[{ }_{s} p_{x}(t) \times\left(1+r_{t}\right)^{-(s+0.5)} \mid \mathcal{F}_{t}\right]
$$

where $r_{t}$ is the discount interest rate set at $2 \%$ for all years; the survival probability ${ }_{s} p_{x}(t)$ is computed by Statistics Finland based on five-year period life tables, and $\omega$ is the highest attainable age in the Finnish life table $(\omega=100)$.

The Finnish life expectancy coefficient is defined such that the pension wealth adjusted with $S F^{F I N}(t)$ equals the un-adjusted pension wealth of the base year 2009 measured with a two-year lag, i.e., calculated using the period life tables for 2003-2007. The coefficient is calculated at a precision of five decimals. The coefficient applies equally to men and women. The life expectancy coefficient implicitly provides for intergenerational actuarial fairness in that it tries to reconcile the relationship between the contribution effort and pension entitlements across consecutive birth cohorts retiring at the same age, but only in a very approximate way. This is because, abstracting from pension decrements/increments for early/late retirement, the factor $S F^{F I N}(t)$ implicitly assumes that all workers will retire at the same (reference) age. 
Life expectancy increases reduce the value of $\operatorname{SF}^{F I N}(t)$, i.e., they imply lower initial pension benefits for individuals retiring at the same age as previous cohorts. Ceteris paribus, lower initial pensions mean lower pension entitlements (wealth). The Finnish life expectancy coefficient is based on five consecutive years total population period (and not cohort) survival estimates, i.e., it does not take into account expected mortality improvements. As of 2020, the Finnish life expectancy coefficient for the 1958 birth cohort is 0.95404 . Following the 2017 reform, the normal retirement age will be linked to period life expectancy so that the retirement duration as a fraction of the contribution period remains constant over time. As of 2027, changes in the reference pension age $x_{r}$ will be taken into account when computing the life expectancy coefficient and the reference age will be updated to 65 years old:

$$
S F^{F I N}(t):=\frac{\ddot{a}_{62}(2009)}{\ddot{a}_{62}(2026)} \times \frac{\ddot{a}_{65}(2025)}{\ddot{a}_{x_{r}}(t)}, t>2026
$$

Portugal was one the first countries to introduce in 2008 (legislated in 2007) a sustainability factor adjusting, for new retirees, the initial old age pension (and in the original formulation, the disability pension when converting to an old age pension) to life expectancy developments computed at the age of 65 , the then normal retirement age. This policy was part of a larger parametric reform package that included a redistributive accrual rate scheme linked to earned income, moving progressively from best-years to a full career when computing the pensionable wage, tightening the actuarial link between earned income and pension entitlements, and introducing penalties (bonus) for early (deferred) retirement. The DB pension benefit formula in Portugal is as follows [48]:

$$
P_{x_{r}(t)}=\theta_{t}\left(x_{r(t)}-x_{e}\right) \cdot \overline{R E}_{x_{r}(t)} \cdot S F^{P O R}(t) \cdot b_{x_{r}(t)},
$$

where $\theta_{t}$ is a non-linear accrual rate schedule for each year of service (accrual rates per year range between $2 \%$ for higher wages and $2.3 \%$ for lower wages), $\left(x_{r(t)}-x_{e}\right)$ is the contribution period, $S F^{P O R}(t)$ is the sustainability factor, $b_{x_{r}(t)}$ are pension decrements (increments) for early $\left(b_{x_{r}(t)}<1\right)$ or postponed $\left(b_{x_{r}(t)}>1\right)$ retirement, and $\overline{R E}_{x_{r}(t)} \equiv \overline{R E}\left(x_{r(t)}, x_{e}, w_{t}, v_{t}\right)$ is the lifetime average revalued earnings $\overline{R E}_{x_{r}(t)}=\frac{R E_{x_{r}(t)}}{x_{r}(t)-x_{e}}$ with

$$
R E_{x_{r}(t)}=\left(w_{t}^{x_{r}(t)}+\sum_{x=x_{0}}^{x_{r}(t)-1} w_{t-x_{r}(t)+x}^{x_{r}(t)} \prod_{j=t-x_{r}(t)+x+1}^{t}\left(1+v_{j}\right)\right),
$$

where $v_{t}$ denotes the factor by which each year's contributions are revalued (a combination between the Consumer Price Index (CPI) and productivity growth).

The sustainability factor is defined as the ratio between the total population period life expectancy computed by Statistics Portugal at the age of 65 in the base year (initially 2006, changed to 2000 in 2014), $\dot{e}_{65}^{P}(2000)$, and the period life expectancy computed at the same age in the year before the insured reaches the set retirement age, $\dot{e}_{65}^{P}(t-1)$. Formally, it is defined as:

$$
\operatorname{SF}^{P O R}(t):=\frac{\dot{e}_{65}^{P}(2000)}{\dot{e}_{65}^{P}(t-1)}
$$

The coefficient applies equally to men and women. By law, the sustainability factor is revised every year. The policy design of the Portuguese sustainability factor resembles that originally proposed in Finland, but neglects the time value of money (interest rate) factor, i.e., it implicitly assumes a $0 \%$ interest rate. Assuming that the pension benefit indexation equals the discount interest rate, an assumption that roughly holds for wageindexed pensions, the life annuity factor matches the life expectancy. In that scenario, policy designs (8) and (13) are essentially the same. However, in the Finnish factor design, 
for a given life expectancy trend, the higher the discount interest rate the smaller the impact of longevity improvements on the sustainability factor.

This means that, for a positive interest rate, the effect of equal life expectancy increases at the reference age on the sustainability factor will be higher in countries adopting a policy design based on the ratio between life expectancy values (e.g., Portugal) when compared to countries (e.g., Finland) adopting a policy design based on the ratio between life annuity values. The use of a positive discount rate front-loads pension payments, which benefits short-lived pensioners.

From Equation (13), it follows that period life expectancy improvements reduce the initial pension benefits for individuals retiring at the same age as previous cohorts reducing the replacement rate of pensions. The introduction of the sustainability factor in 2008 was initially combined with the possibility of extending the contribution career to mitigate or offset the pension cuts induced by $S F^{P O R}(t)$. Following the 2013 pension reform, as of 2014, the reference year of the sustainability factor was changed from 2006 to 2000, increasing the (already high) penalties for early retirement. This move was accompanied by a reform indexing the normal pension age to period life expectancy computed at the age of 65 as follows:

$$
x_{r}^{P R T}(t)=66+\frac{2}{3}\left[\dot{e}_{65}^{P}(t-2)-\dot{e}_{65}^{P}(2012)\right] .
$$

The pension age can be reduced for very long contribution careers. On the date when the beneficiary reaches 60 years of age, the normal state pension age is reduced by four months for every calendar year (with registered earnings) worked in excess of the contributions ceiling of 40 years. In compensation, the factor was abolished from the DB formula for individuals retiring at the normal (statutory) retirement age, continuing only for individuals retiring early and for disability pensions converting to old age pensions at the age of 65. Since October 2017, the sustainability factor is no longer applied to disability pensions converting to old age pensions. Since 2020, workers in hazardous jobs and with very long contribution careers (with at least 40 contribution years computed when completing 60 years old) were also exempted from the sustainability factor. As of 2020, the Portuguese sustainability factor is 0.8480 , i.e., the initial pension benefit of individuals retiring early in 2021 is reduced by $15.2 \%$, on top of penalties of $0.5 \%$ per month of early retirement. The factor generates significant pension entitlement reductions for early retirement and has not been designed to adjust pension systems consistent with actuarial intergenerational fairness and neutrality principles [49].

In 2013, Spain introduced a sustainability factor adjusting the initial old age pension benefit to life expectancy improvements computed at the age of 67 , as part of a broader pension reform introducing an automatic balancing mechanism (ABM) linking pension indexation to the scheme's total contribution revenue, pension expenditures, the financial balance of pensions and of the Social Security system and the CPI. In addition, in 2011, another reform had already been carried out to increase the contribution years required for a full pension, moving progressively from best-years to a full career when computing the pensionable wage, gradually increasing the retirement age. The Spanish sustainability factor was a function of the annual average variation in the period life expectancy of the population of pensioners affiliated with the general social security scheme computed at the reference age of 67 over 5 years, measured with a two-year lag, as follows:

$$
S F^{E S P}(t):=S F^{E S P}(t-1) \times\left[\frac{\dot{e}_{67}^{P}(\tau-5)}{\dot{e}_{67}^{P}(\tau)}\right]^{\frac{1}{5}}, \tau<t,
$$

where $S F^{E S P}(t-1)$ is the sustainability factor in year $t-1$, with $S F^{E S P}(2018)=1$. The coefficient applies equally to men and women. The effective introduction of the sustainability factor was planned for 2019, but it has been suspended sine die, and the reform proposed by the current government in Spain rules out its use. For example, in 2019, the factor would 
be equal to the ratio $\left[\dot{e}_{67}^{P}(2012) / \dot{e}_{67}^{P}(2017)\right]^{\frac{1}{5}}$, meaning that period life expectancy increases observed between 2012 and 2017 would have reduced initial pension benefits for those retiring from 2019 onward. In 2020, the sustainability factor will be that corresponding to 2019 multiplied by the same ratio. By law, the sustainability factor should be revised every five years, so that in 2024 it will correspond to $\left[\dot{e}_{67}^{P}(2017) / \dot{e}_{67}^{P}(2022)\right]^{\frac{1}{5}}$, and so on. The sustainability factor in Spain was linked to the (smoothed) period and not cohort survival improvements, just like in Portugal and Finland. The difference is that in the Spanish case the population considered was not the country's total population, but the pensioners' population, which at these ages is naturally highly correlated with the total population. Recent estimates [50] suggest that the factor adoption in Spain would have reduced the annual pension expenditure by approximately $1 \%$ of GDP.

Other countries have introduced automatic indexation mechanisms indirectly linking pensions to life expectancy. For instance, Germany introduced in 2004 a factor linking pension benefits to the number of equivalent pensioners per number of equivalent contributors. In Sweden, Poland, Italy, Latvia, and Norway, the non-financial defined contribution (NDC) system automatically links pension benefits to each birth cohort life annuity factor, which embeds period life expectancy estimates. In Sweden, in addition, there is an automatic adjustment of all (new and existing) pensions to the balance ratio of the NDC scheme, which is impacted by population aging and extended survival prospects. In Estonia, Lithuania, the Netherlands, Japan, and Luxembourg, all pensions are indexed either to the financial balance of the pension system, to demographic ratios, to CPI or the wage bill [2].

\subsection{A Bayesian Model Averaging Approach to Stochastic Mortality Forecasting}

This section draws heavily and resumes the Bayesian Model Averaging approach for stochastic mortality modeling and forecasting developed in [18] and applied in this study. The rationale behind BMA is that instead of producing best-estimate forecasts based on a single believed to be best model, model combination aims at finding a composite model that better approximates the actual data generation process and its multiple sources of risk. The BMA composite model is set to be superior to the single candidate models because, first, it explicitly addresses model risk, i.e., conceptual uncertainty. Second, because each model deficiencies are ideally compensated within an appropriate combination. Third, because conditioning the statistical inference on a set of statistical models minimizes the biases and produces more realistic confidence intervals. This will ultimately improve the out-of-sample forecasting accuracy and provide a more accurate representation of the forecast uncertainty for decision-making.

The standard BMA approach consists of applying the Bayesian theory to model selection and inference by weighing each model by its posterior model probability. This differentiates from alternative ensemble learning strategies, such as (i) bootstrap aggregating (bagging), which considers homogeneous weak learners, learns them independently in parallel (and not concurrently) using a bootstrapping (with replacement) process, and combines (aggregates) them using some predefined averaging process; (ii) boosting algorithms, which operate in the same essence as bagging methods, but aiming at reducing variance and bias; and (iii) stacking methods that differentiate from bagging and boosting by considering heterogeneous weak learners and a meta-model to combine them.

Let $M_{l}(l=1, \ldots, K)$ represent each candidate model. This encompasses the set of probability distributions comprehending the likelihood function $\mathcal{L}\left(y \mid \xi_{l}, M_{l}\right)$ of the response variable $y$ in terms of model-specific parameters $\xi_{l}$, and $\pi\left(\xi_{l}, M_{l}\right)$ is the prior density of $\xi_{l}$ under $M_{l}$. Let $\Delta$ denote a quantity of interest included in all models, but not model-specific, for instance, the predictive quantity of $y$. The marginal posterior distribution across all models is given by [51]:

$$
\pi(\Delta \mid y)=\sum_{k=1}^{K} \pi\left(\Delta \mid y, M_{k}\right) \pi\left(M_{k} \mid y\right)
$$


where $\pi\left(\Delta \mid y, M_{k}\right)$ is the forecast PDF obtained from model $M_{k} ; \pi\left(M_{k} \mid y\right)$ is the posterior probability of model $M_{k}$ estimated from data ("lookforward window" in case of sequential data). The posterior probability for model $M_{k}$ is given by

$$
\pi\left(M_{k} \mid y\right)=\frac{\pi\left(y \mid M_{k}\right) \pi\left(M_{k}\right)}{\sum_{l=1}^{K} \pi\left(y \mid M_{l}\right) \pi\left(M_{l}\right)},
$$

where $\pi\left(M_{k}\right)$ is a prior probability for $M_{k}$ and $\pi\left(y \mid M_{k}\right)$ the marginal likelihood for $M_{k}$. The posterior model probabilities add up to one, i.e., $\sum_{k=1}^{K} \pi\left(M_{k} \mid y\right)=1$ and are, thus, interpreted as weights. The prior structures convey the initial beliefs (before the data have been seen) about the relative plausibility of models and/or parameter values.

In the first stage, we select the subset of models to be part of the model combination (model confidence set) by ranking them according to out-of-sample predictive accuracy. We implement a backtesting procedure considering a common 5-year forecasting horizon for all models and populations. The forecasting accuracy is measured using the symmetric mean absolute percentage error (SMAPE). Secondly, we compute the posterior probability for each model using the normalized exponential function

$$
\pi\left(M_{k} \mid y\right)=\frac{\exp \left(-\left|\varphi_{k}\right|\right)}{\sum_{l=1}^{K} \exp \left(-\left|\varphi_{l}\right|\right)}
$$

with $\varphi_{k}=S_{k} / \max \left\{S_{l}\right\}_{l=1, \ldots, K}(k=1, \ldots, K) ; S_{k}$ is the SMAPE value for model $k$.

Finally, in step 3 , the composite BMA point forecast is obtained by probabilistically combining the $K$ individual models. The MATA methodology is adopted to derive modelaveraged Bayesian credible intervals [46]. The method involves averaging the tail areas of the sampling distributions of individual-model estimates to produces the required overall error rate using the BMA posterior probability as weights.

\subsubsection{Individual Stochastic Mortality Models}

The principle of model averaging implicitly assumes a well-defined model space (MS), typically a finite but potentially sizable set of single models. However, we note that, in some cases, it is possible to construct an infinite space of models, for instance, by considering a given family of transformations (e.g., the Box-Cox family) of the response variable. Three main types of uncertainty may be considered in defining the model space: (i) theory or conceptual uncertainty, (ii) specification uncertainty (e.g., alternative functional forms, extended versus reduced models), and (iii) Heterogeneity uncertainty if the underlying stochastic process is not homogeneous. The selection of the model space should be careful since complexity and overfitting are penalized.

The empirical strategy adopted in this study requires the selection of a subset of single population heterogeneous stochastic mortality models to be part of the model combination. In defining the model space, we account for both conceptual uncertainty and specification uncertainty. The model space used in this study comprises a selection of well-known and commonly used GAPC parametric models, smoothing approaches, and principal component methods. Table 1 summarizes the analytical structure of the single forecasting methods used in this study. Appendix A complements the information with a brief technical description of each model.

The model space comprises six single-population GAPC models: (LC) the age-period Lee-Carter model assuming a Poisson distribution for death counts [26,35], imposing no smoothness across ages or years; (APC) the simple age-period-cohort model [30]; $(\mathrm{RH})$ the LC model including cohort effects [40]; (CBD) the Cairns-Blake-Dowd model with two correlated factors (level and slope) and simple age effects imposing smoothness across ages in the same year, considering a particular predictor structure obtained by setting $\beta_{x}^{(1)}=1$ and $\beta_{x}^{(2)}=(x-\bar{x})$, with $\bar{x}$ the average age in the data [52]; (M7) the CBD model including a non-linear (quadratic) age effect and cohort effects [27]; (Plat) a three-period factor model featuring dependence between the mortality rates observed at different ages [39]. 
The model space also includes (HUw) the Functional Demographic Model with geometrically decaying weights [32]; (RSVD) the regularized singular value decomposition model, a bivariate functional data model [31,41]; (CPspl) the two-dimensional smooth constrained P-splines model [29]. The specification is complemented with assumptions regarding the statistical distribution (Poisson, Binomial) of the number of deaths and a set of parameter constraints to guarantee unique parameter estimates. A fixed-rule trimming scheme by which, for each population, three out of the six individual GAPC models are discarded based on their out-of-sample forecasting performance, is adopted to account for the existence of nested models.

Table 1. Stochastic mortality model space.

\begin{tabular}{cl}
\hline Model & \multicolumn{1}{c}{ Model Structure } \\
\hline LC & $\eta_{x, t}=\alpha_{x}+\beta_{x}^{(1)} \kappa_{t}^{(1)}$ \\
APC & $\eta_{x, t}=\alpha_{x}+\kappa_{t}^{(1)}+\gamma_{t-x}$ \\
RH & $\eta_{x, t}=\alpha_{x}+\beta_{x}^{(1)} \kappa_{t}^{(1)}+\beta_{x}^{(0)} \gamma_{t-x}$ \\
CBD & $\eta_{x, t}=\kappa_{t}^{(1)}+(x-\bar{x}) \kappa_{t}^{(2)}$ \\
M7 & $\eta_{x, t}=\kappa_{t}^{(1)}+(x-\bar{x}) \kappa_{t}^{(2)}+\left((x-\bar{x})^{2}-\sigma_{x}^{2}\right) \kappa_{t}^{(3)}+\gamma_{t-x}$ \\
Plat & $\eta_{x, t}=\alpha_{x}+\kappa_{t}^{(1)}+(x-\bar{x}) \kappa_{t}^{(2)}+(\bar{x}-x)^{+} \kappa_{t}^{(3)}+\gamma_{t-x}$ \\
HUw & $y_{t}\left(x_{i}\right)=f_{t}\left(x_{i}\right)+\sigma_{t}\left(x_{i}\right) \epsilon_{t, i}$ \\
CPspl & $\eta=B \alpha$ \\
RSVD & $m(x, t)=\sum_{j=1}^{q} d_{j} U_{j}(t) V_{j}(x)+\epsilon(x, t)$ \\
\hline
\end{tabular}

Note: $\eta_{x, t}$ denotes the linear predictor; $\alpha_{x}$ and $\beta_{x}^{(i)}$ denote age-specific terms; $\kappa_{t}^{(i)}$ and $\gamma_{t-x}$ are period and cohort indices; $\sigma_{x}^{2}$ is the mean of $(x-\bar{x})^{2} ; y_{t}\left(x_{i}\right)=\log \left(m_{x_{i}, t}\right) ; f_{t}\left(x_{i}\right)$ is a continuous and smooth function; $\sigma_{t}\left(x_{i}\right)$ is a volatility term; $\epsilon_{t, i}$ and $\epsilon(x, t)$ are error terms; $\mathbb{B}$ are B-spline bases with a roughness penalty; $\alpha$ is a vector of parameters. Source: [9].

To generate forecasts of age-specific mortality rates, we first calibrate the single models using each country's total population data in the age range 60-95 from 1960 to the most recent year available. A bootstrap methodology considering 5000 bootstrap samples is used to derive prediction intervals for age-specific mortality rates. The life tables for all three countries are closed at the maximum age of 125 using the following log-quadratic regression [53]:

$$
\ln \left(q_{x}(t)\right)=a+b x+c x^{2}+\epsilon_{x}, \epsilon_{x} \sim \mathcal{N}\left(0, \sigma^{2}\right)
$$

with constraints $q_{x_{\max }}(t)=1$ and $\frac{\delta q_{x_{\max }}(t)}{\delta t}=0$.

\subsubsection{Data}

The datasets used in this study are from the Human Mortality Database [54], consisting of observed death counts, $D_{x, t}$, and exposure-to-risk, $E_{x, t}$, classified by age at death $(x=0, \ldots, 110+)$, year of death $(t=1960, \ldots, 2019)$ and sex, and normal retirement age data collected from National Statistical Offices (NSOs) and social security bureaus. For Spain, we use total population data as a proxy of pensioner data, since the latter are not publicly available. The model fitting, forecasting, and simulation procedures, and additional computations have been implemented using an $\mathrm{R}$ software routine.

\section{Results}

Figure 1 represents, for the total population of Finland, the point forecasts of agespecific log-mortality rates by year in the age interval 60-95 years old, derived from the nine individual candidate stochastic mortality models considered in this study. We can observe that all models forecast a decline in age-specific mortality rates in Finland, with larger longevity improvements expected between ages 60 and 80. Similar results were obtained for the total population of Spain and Portugal and by sex. 


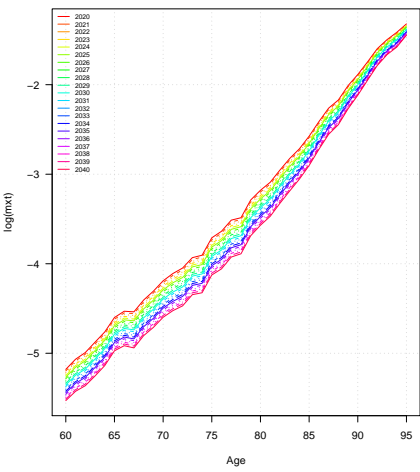

Plat

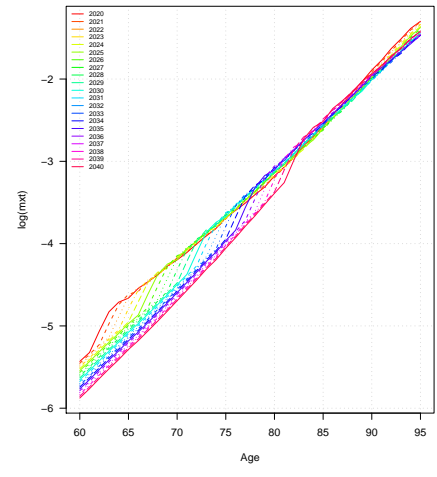

HUw

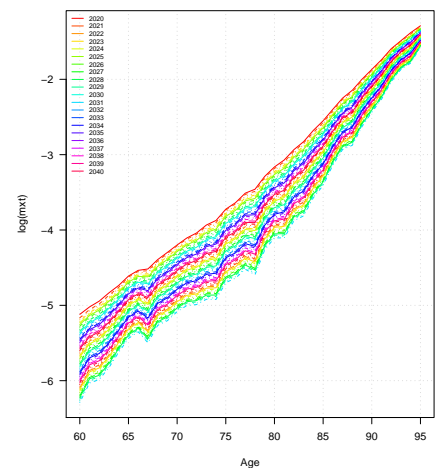

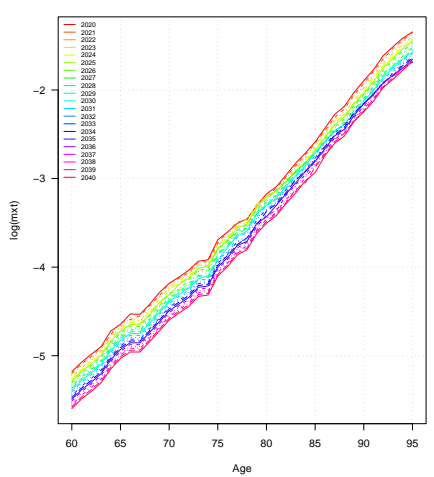

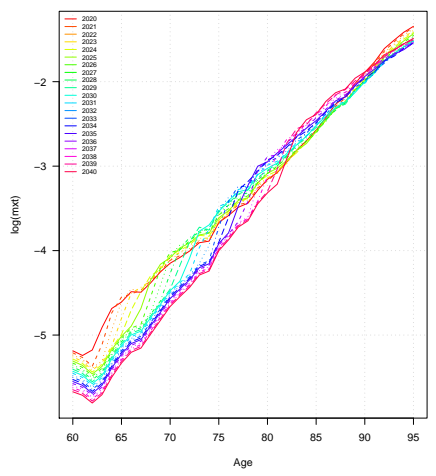

CP-Splines

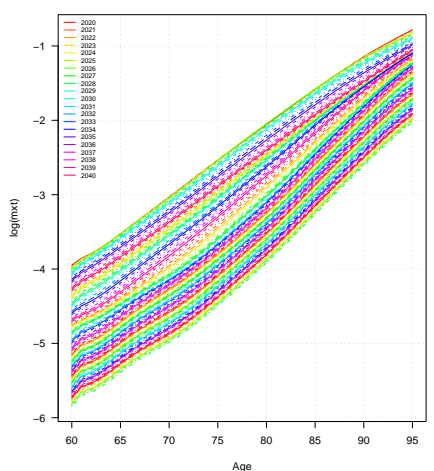

CBD

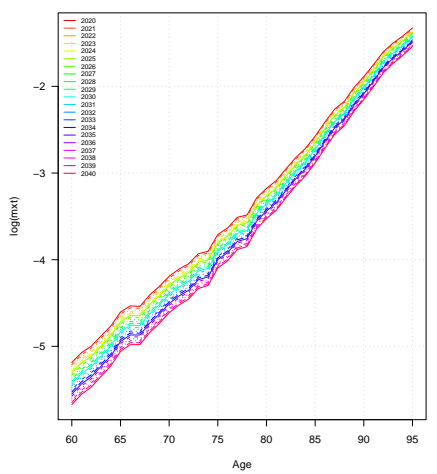

RH

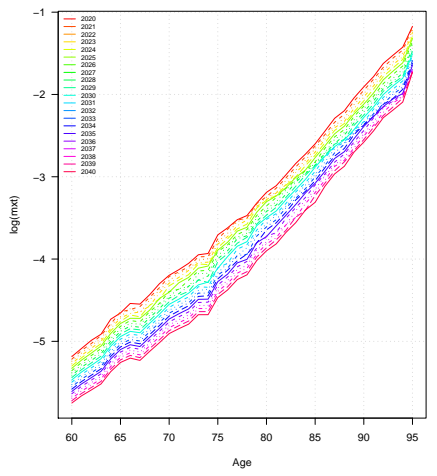

RSVD

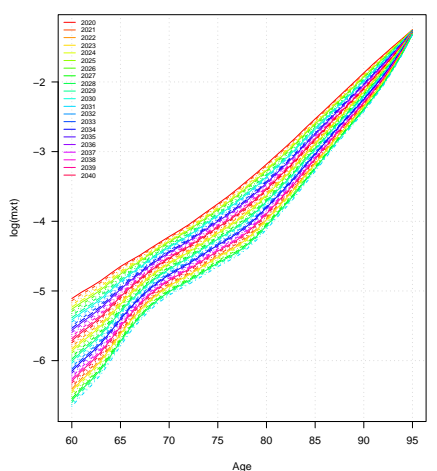

Figure 1. Stochastic mortality model forecasting results for selected years, Finland.

Figure 2 plots, in the vertical axis, the subset of models selected by the BMA procedure - the model confidence set-for the total populations of Finland, Portugal, and Spain together with, in the horizontal axis, the corresponding BMA posterior probabilities (model weights). The results show that the set of best-performing forecasting models varies between countries, i.e., their predictive performance is population specific. This is explained by the differential patterns of age, time, and cohort effects in mortality observed in the data. The variability in out-of-sample forecasting accuracy of the models also reveals their ability to apprehend diverse features of mortality data. For instance, models with substantial age-period parameters, such as Plat and M7, tend to fit better the cross-section of the mortality curve, but exhibit poorer out-of-sample performance, often overfitting, whereas models with fewer age-period terms, such as LC and APC, tend to capture better the long-term trends in longevity and the annual noise in the data. The non-parametric approaches, such as CP-Splines and RSVD, tend to capture better nonlinearities in the data (e.g., the accident mortality hump at young ages). This means combining models is a way to leverage their strengths and minimize their downsides. The results obtained in this dataset show that no individual stochastic model dominates based on the predictive accuracy criteria, with the CP-Splines and the weighted Hyndman-Ullah models providing 
consistently good results across populations and the Plat model generating the worst forecasting performance. We note that the forecasting results do not incorporate the effects of the pandemic on mortality rates. Recent projections by national statistical offices (e.g., the Spanish NSO) indicate that the long-term effect of the pandemic on life expectancy prospects is relatively small once mortality rates return to pre-pandemic values.
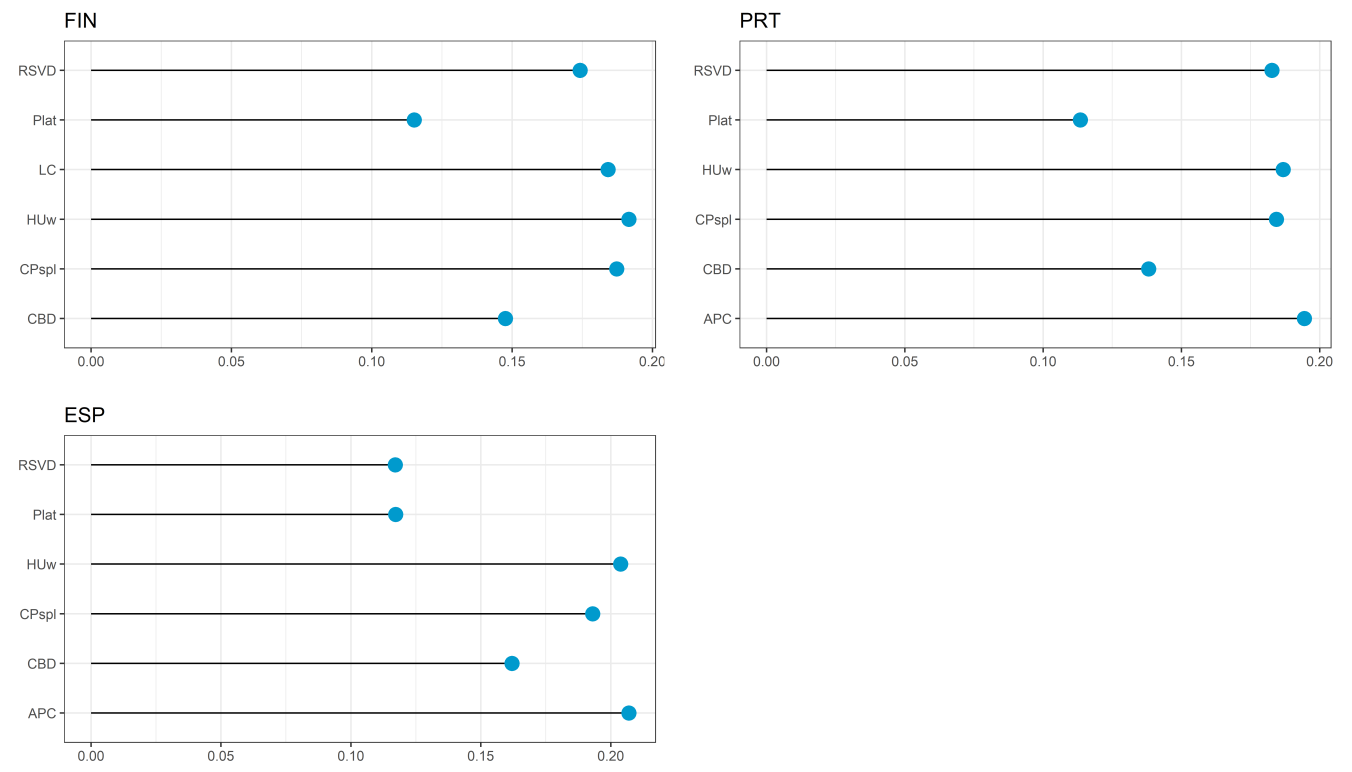

Figure 2. Model confidence set with corresponding model posterior probability. Notes: FIN = Finland, PRT $=$ Portugal ESP $=$ Spain. The model weights are expressed in percentages and represented in the horizontal axis.

Figure 3 plots for Finland, first, the BMA forecast of the unisex period and cohort life expectancy measures at the sustainability factor reference indexation age (62 years old) from 2020 to 2050, together with the corresponding 95\% MATA confidence intervals (left panel). Second, it represents the observed and forecasted values of the sustainability factor from 2009 to 2050 computed using the actual policy design, i.e., using a period (PER) approach when computing the life annuity factors in Equations (8) and (10), along with the corresponding $95 \%$ prediction intervals, and forecasts of the sustainability factor in a counterfactual scenario in which we apply the same factor definition but use cohort $(\mathrm{COH})$ life expectancy estimates at the age of 62 as an alternative measure of the remaining lifetime at retirement ages (right panel). The results show that both period and cohort life expectancy are expected to consistently increase in Finland in the next decades. In Finland, the period (cohort) life expectancy at the age of 62 is forecasted to increase from 22.88 (24.66) years in 2020 to 26.35 (28.38) years in 2050. The life expectancy gap in Finland is forecasted to grow from 1.79 years in 2020 to 2.03 years in 2050, representing an implicit tax of $7.71 \%$ from future to current pensioners at the end of the forecasting horizon.

As of 2020, the Finnish life expectancy coefficient is 0.95404 , which results in a reduction of $4.60 \%$ in the initial pension for the 1958 birth cohort (Table 2). We forecast that the life expectancy coefficient will decline to 0.9173 in 2030, to 0.8817 in 2040, and to 0.8487 in 2050 , generating benefit cuts of $8.27 \%, 11.83 \%$, and $15.13 \%$, respectively. In a counterfactual scenario in which a cohort approach is pursued to compute the sustainability factor, we forecast that the benefit cuts would have been slightly higher than those computed using a period approach, a result that is explained by the increasing life expectancy gap forecasted at the reference age. To mitigate or overcome the diminishing effect of the life expectancy coefficient on old age entry pension levels, workers may extend their working life for as long as necessary to get a full pension. 

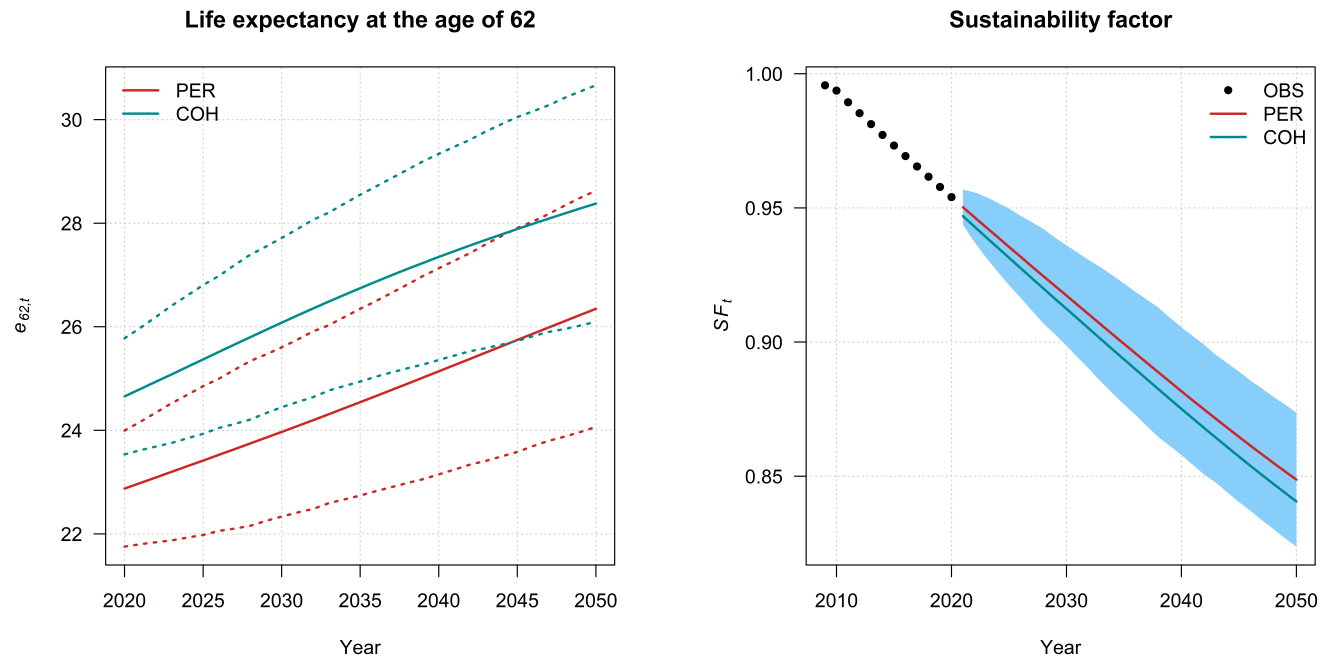

Figure 3. Finland: forecasts of the life expectancy and sustainability factor. Notes: the solid lines in the left panel represent the period (PER) or cohort (COH) life expectancy estimates at the age of 62, with the dashed lines representing the corresponding 95\% MATA prediction intervals. In the right panel, the dots correspond to the observed values of the life expectancy coefficient. Computations are based on 1-year life expectancy and life annuity estimates rather than the 5-year estimates used in Finland.

Table 2. Finland: Sustainability factor, pension cuts, and extra working years required.

\begin{tabular}{ccccccc}
\hline \multirow{2}{*}{ Year } & \multicolumn{2}{c}{ Sustainability Factor } & \multicolumn{2}{c}{ Pension Cut (\%) } & \multicolumn{2}{c}{ Extra Working Years } \\
\cline { 2 - 7 } & Period & Cohort & Period & Cohort & Period & Cohort \\
\hline 2009 & 1.0000 & 1.0000 & 0.00 & 0.00 & 0.000 & 0.000 \\
2010 & 0.9917 & 0.9925 & 0.83 & 0.75 & 0.174 & 0.157 \\
2015 & 0.9720 & 0.9710 & 2.80 & 2.90 & 0.600 & 0.621 \\
2020 & 0.9540 & 0.9509 & 4.60 & 4.91 & 1.004 & 1.077 \\
2025 & 0.9355 & 0.9314 & 6.45 & 6.86 & 1.437 & 1.534 \\
2030 & 0.9173 & 0.9124 & 8.27 & 8.76 & 1.878 & 2.001 \\
2035 & 0.8993 & 0.8936 & 10.07 & 10.64 & 2.332 & 2.482 \\
2040 & 0.8817 & 0.8751 & 11.83 & 12.49 & 2.796 & 2.974 \\
2045 & 0.8647 & 0.8573 & 13.53 & 14.27 & 3.260 & 3.467 \\
2050 & 0.8487 & 0.8406 & 15.13 & 15.94 & 3.714 & 3.951 \\
\hline
\end{tabular}

Notes: computations based on 1-year life annuity estimates rather than the 5-year estimates used in Finland. The extra working years required to offset the benefit cuts caused by the sustainability factor in a given calendar year and to get a full pension are computed considering the current increment/bonus for late retirement in Finland (4.8\% per year). We assume that the extra work years do not change the average lifetime revalued earnings at the retirement age.

As of 2020, we estimate that, to fully offset the sustainability factor effect in the DB formula, Finnish workers will have to postpone their retirement by 1.004 years (1.077 years under a cohort approach) to get a full pension. We forecast that in 2050, the increment in the retirement age required to offset the cutting effect of the sustainability factor on pension entry levels is 3.714 years. Stated differently, the so-called "target retirement age" in Finland is forecasted to be 3.714 years higher than the birth cohort normal retirement age. This value is slightly higher if we use the cohort approach, 3.951 years.

Figure 4 plots, for Portugal, the BMA forecast of the unisex period and cohort life expectancy measures at the sustainability factor reference indexation age (65 years old) from 2020 to 2050, together with the corresponding 95\% MATA confidence intervals (left panel), along with the observed and forecasted values of the sustainability factor from 2008 to 2050 computed using the actual policy design, i.e., using a period (PER) approach when computing life expectancy in Equation (13). As for the case of Finland, we also report 
forecasts of the sustainability factor in a counterfactual scenario in which cohort $(\mathrm{COH})$ life expectancy estimates at the age of $65 \mathrm{had}$ been considered in the computation of the sustainability factor. We forecast that both the period and the cohort life expectancy at the age of 65 will continue to increase in the next decades, following observed historical trends in longevity at retirement ages recorded in Portugal. The unisex period (cohort) life expectancy at the age of 65 is forecasted to augment from 20.25 (21.59) years in 2020 to 23.30 (25.04) years in 2050. The life expectancy gap in the country is forecasted to grow from 1.34 years in 2020 to 1.74 years in 2050, representing an implicit tax of $7.48 \%$ from future to current pensioners in 2050.
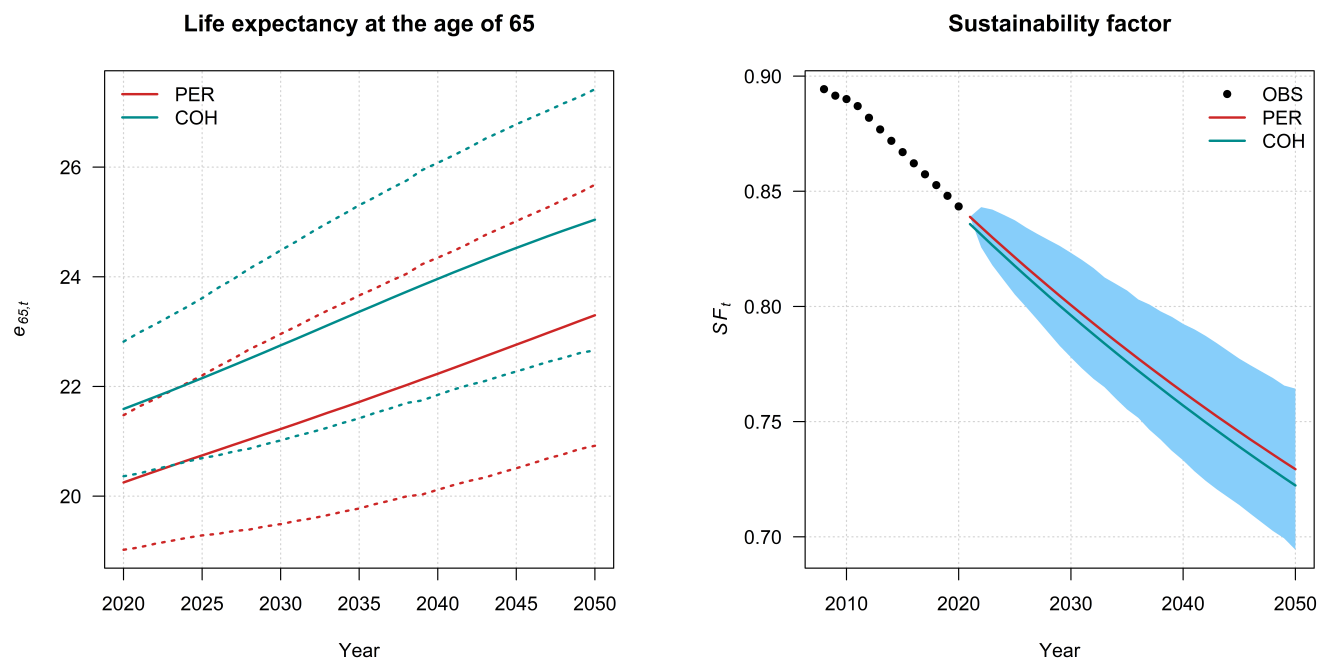

Figure 4. Portugal: forecasts of the life expectancy and sustainability factor. The solid lines in the left panel represent the period (PER) or cohort $(\mathrm{COH})$ life expectancy estimates at the age of 65 , with the dashed lines representing the corresponding 95\% MATA prediction intervals. In the right panel, the dots correspond to the observed values of the sustainability factor.

As of 2020, the Portuguese life expectancy coefficient is 0.8480 , which results in a reduction of $15.20 \%$ in the initial pension for workers retiring in advance of the then common normal retirement age of 66.5 years (Table 3). We forecast that the life expectancy coefficient will decline to 0.8006 in 2030, to 0.7628 in 2040, and 0.7294 in 2050, generating benefit cuts of $19.94 \%, 23.72 \%$, and $27.06 \%$, respectively. In a counterfactual scenario in which a cohort approach had been used to compute the sustainability factor, we forecast that the entry pension cuts would have been marginally higher than those computed using a period approach, a result that is once again justified by the increasing life expectancy gap forecasted at the reference age of 65 in Portugal.

To mitigate the pension wealth reduction produced by the sustainability factor, as of 2020 we estimate that Portuguese workers will need to postpone their retirement age by 2.987 years (3.052 years under a cohort approach) to get a full pension. Extending working lives to compensate for the benefit reduction caused by the life expectancy coefficient is going to become even more important in the future for Portuguese workers. We forecast that, in 2050, to fully compensate for the sustainability factor effect, workers will have to postpone their retirement age by 6.184 years (Table 3). The extra working years add to those predicted as part of the automatic indexation of the retirement age mechanism in place since 2014, under which the normal pension age is forecasted to reach 68 years and 5 months by 2050 . 
Table 3. Portugal: Sustainability factor, pension cuts, and extra working years required.

\begin{tabular}{ccccccc}
\hline \multirow{2}{*}{ Year } & \multicolumn{2}{c}{ Sustainability Factor } & \multicolumn{2}{c}{ Pension Cut (\%) } & \multicolumn{2}{c}{ Extra Working Years } \\
\cline { 2 - 6 } & Period & Cohort & Period & Cohort & Period & Cohort \\
\hline 2000 & 1.0000 & 1.0000 & 0.00 & 0.00 & 0.000 & 0.000 \\
2008 & 0.8943 & 0.8934 & 10.57 & 10.66 & 1.969 & 1.988 \\
2010 & 0.8900 & 0.8887 & 11.00 & 11.13 & 2.060 & 2.086 \\
2015 & 0.8670 & 0.8649 & 13.30 & 13.51 & 2.557 & 2.604 \\
2020 & 0.8480 & 0.8452 & 15.20 & 15.48 & 2.987 & 3.052 \\
2025 & 0.8213 & 0.8176 & 17.87 & 18.24 & 3.626 & 3.718 \\
2030 & 0.8006 & 0.7961 & 19.94 & 20.39 & 4.151 & 4.268 \\
2035 & 0.7811 & 0.7760 & 21.89 & 22.40 & 4.670 & 4.812 \\
2040 & 0.7628 & 0.7570 & 23.72 & 24.30 & 5.183 & 5.350 \\
2045 & 0.7456 & 0.7391 & 25.44 & 26.09 & 5.687 & 5.882 \\
2050 & 0.7294 & 0.7223 & 27.06 & 27.77 & 6.184 & 6.408 \\
\hline
\end{tabular}

Notes: the extra working years required to offset the benefit cuts caused by the sustainability factor in a given calendar year and to get a full pension are computed considering a $6 \%$ increment/bonus for late retirement. In Portugal, the bonuses for late retirement are linked to the length of the contribution career and range from a minimum of $0 \%$ per year for short careers to a maximum of $12 \%$ per year for long careers ( 40 or more contribution years). Since 2013, benefit cuts are applied only to early retirement pensions. We assume that the extra work years do not change the average lifetime revalued earnings at the retirement age.

Finally, Figure 5 plots, for Spain, the BMA forecast of the total population period and cohort life expectancy measures at the sustainability factor reference indexation age (67 years old) from 2020 to 2050, together with the corresponding 95\% MATA confidence intervals (left panel). As before, we represent the "observed" (assuming the factor had not been suspended in 2019) and the forecasted values of the sustainability factor from 2019 to 2050 computed using the actual policy design, i.e., using a period (PER) approach to life expectancy computation in Equation (15). As for the case of Finland and Portugal, we also report forecasts of the sustainability factor in a counterfactual scenario in which cohort (COH) life expectancy estimates at the age of 67 had been used in Equation (15). We predict that both the period and the cohort life expectancy at the age of 67 will maintain its long-term positive trend in Spain, which is already one of the leading countries in the world in terms of population longevity. The unisex period (cohort) life expectancy at the age of 67 is forecasted to increase from 19.97 (21.12) years in 2020 to 22.51 (23.77) years in 2050. The life expectancy gap in Spain is forecasted to marginally grow from 1.21 years in 2020 to 1.26 years in 2050, representing an implicit tax of 5.60\% from future to current pensioners at that time.

Under the current policy design, we estimate that the sustainability factor in Spain in 2020 would have been 0.9882 had it not been suspended, generating a 1.18\% reduction in the entry pension level of all pensioners retiring in that year (Table 4). We forecast that the sustainability factor will decline to 0.9335 in 2030, to 0.8950 in 2040, and 0.8608 in 2050, reducing entry pensions by $6.65 \%, 10.50 \%$, and $13.92 \%$, respectively. In a counterfactual scenario in which cohort life expectancy had been used to compute the sustainability factor, we forecast that pension cuts would be marginally higher than those computed under the current policy design. The empirical results suggest that the Spanish design of the sustainability factor is relatively insensitive to the use of a period rather than a cohort approach to life expectancy computation. This is because, first, the life expectancy gap at the reference age of 67 is predicted to remain roughly constant in the next decades and, second, the five-year average formula smooths the observed annual variation in life expectancy. To counteract the pension cuts produced by the sustainability factor, we estimate that, as of 2030, Spanish workers will have to postpone their retirement age by 1.78 years (1.826 years under a cohort approach) to get a full pension. Otherwise, they must accept a $6.65 \%$ reduction in their entry (with an impact on subsequent) pension benefits. Since life expectancy is projected to increase in the future, prolonging working lives will become even more important to counteract the cutting effect of the life expectancy coefficient. For 
Spain, we forecast that in 2050, workers will have to postpone their retirement age by 4.042 years to fully compensate for the sustainability factor effect (Table 4).
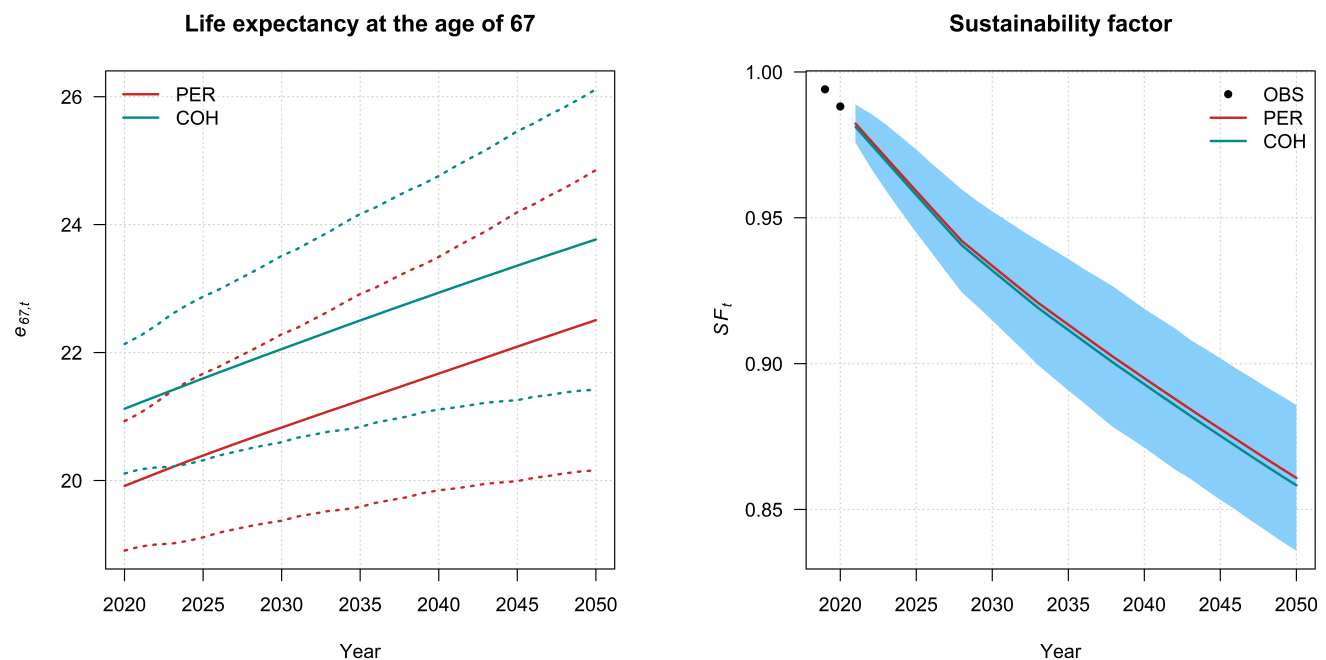

Figure 5. Spain: forecasts of the life expectancy and sustainability factor. Notes: the solid lines in the left panel represent the period (PER) or cohort (COH) life expectancy estimates at the age of 67, with the dashed lines representing the corresponding 95\% MATA prediction intervals. In the right panel, the dots correspond to the actual values of the sustainability factor had it not been suspended.

Table 4. Spain: sustainability factor, pension cuts, and extra working years required.

\begin{tabular}{ccccccc}
\hline \multirow{2}{*}{ Year } & \multicolumn{2}{c}{ Sustainability Factor } & \multicolumn{2}{c}{ Pension Cut (\%) } & \multicolumn{2}{c}{ Extra Working Years } \\
\cline { 2 - 7 } & Period & Cohort & Period & Cohort & Period & Cohort \\
\hline 2018 & 1.0000 & 1.0000 & 0.00 & 0.00 & 0.000 & 0.000 \\
2019 & 0.9941 & 0.9931 & 0.59 & 0.69 & 0.149 & 0.174 \\
2020 & 0.9882 & 0.9871 & 1.18 & 1.29 & 0.299 & 0.326 \\
2025 & 0.9591 & 0.9578 & 4.09 & 4.22 & 1.065 & 1.101 \\
2030 & 0.9335 & 0.9319 & 6.65 & 6.81 & 1.780 & 1.826 \\
2035 & 0.9133 & 0.9115 & 8.67 & 8.85 & 2.372 & 2.427 \\
2040 & 0.8950 & 0.8929 & 10.50 & 10.71 & 2.933 & 2.998 \\
2045 & 0.8776 & 0.8752 & 12.24 & 12.48 & 3.488 & 3.564 \\
2050 & 0.8608 & 0.8583 & 13.92 & 14.17 & 4.042 & 4.129 \\
\hline
\end{tabular}

Notes: the extra working years required to offset the benefit cuts caused by the sustainability factor in a given calendar year and to get a full pension are computed considering the current increment/bonus for late retirement in Spain ( $4 \%$ per year). We assume that the extra work years do not change the average lifetime revalued earnings at the retirement age.

\section{Discussion and Conclusions}

\subsection{Discussion}

The purpose of linking initial and subsequent pension benefits, retirement ages, the contribution length, or the annual pension indexation to life expectancy developments observed at retirement ages is primarily to automatically mitigate the impact of demographic, economic, and financial shocks on the financing of public and private pension schemes. The policy transfers, directly and/or indirectly, part of the systematic risks and of the financial burden of expanding and uncertain lifetime prospects to pensioners, which are ultimately the recipients of longer lives. The development of longevity risk-sharing pensions is seen as one attempt to preserve the welfare-enhancing nature of pension annuities. The introduction of automatic adjustment mechanisms reduces the uncertainty in pensions.

In pay-as-you-go DB schemes, the introduction of automatic stabilizers linked to demographic and/or economic shocks is also viewed as a means to address intergenerational 
fairness concerns flexibly and transparently, introducing actuarial and economic rationality to determine the required changes, strengthening the credibility of the pension promises made to younger generations, on which the stability of the intergenerational social contract ultimately relies on. The introduction of automatic stabilizers replaces regular discretionary measures, which are hard to approve and carry political risks, especially if they involve retrenchments. Unlike discretionary adjustments, a link to life expectancy makes it clear why changes in pensions are necessary and provides a transparent mechanism to regulate the magnitude of the adjustment. If the adjustment is perceived as fair, public support for the reforms is likely to increase.

The way pensions have been linked to longevity markers is not however exempt from several conceptual and policy design flaws, including the use of inappropriate life expectancy measures and longevity heterogeneity. If the adoption of cohort measures better serves policymakers to apprehend the effects of a dynamic population structure, the current preference for period instead of cohort estimates of the remaining lifetime at retirement ages to link pensions to life expectancy is justified either by conceptual uncertainty (model risk) concerns or simply by the lack of cohort estimates at most NSOs.

In this paper, we focused our analysis and discussion on three countries-Finland, Portugal, and Spain - that have introduced an automatic link between entry pension levels and life expectancy or life annuity measures through the so-called sustainability factors, although in the case of Spain the factor has just been repealed. The policy design adopted in the three countries shares some similarities, namely the use of a period approach to survival probability computation, the adoption of a unique reference age (sustainability factor) for all new pensioners, irrespective of the age at which individuals retire, and sex, and the fact that the link is fully automatic and does not require parliamentary approval. Moreover, the three policy designs are symmetrical, i.e., they allow for both downward and upward pension adjustments in case of increases or decreases in life expectancy, respectively.

However, there are important design differences that influence the final policy outcomes. The first refers to the assumption regarding the time value of money (discount interest rate) used to compute the annuity factors, with Portugal and Spain implicitly assuming a zero interest rate and Finland adopting a flat yield curve set at $2 \%$ as the norm. The higher the discount rate embedded in life annuity computations, the smaller the impact of life expectancy increases on sustainability factors and benefit reduction. The discount factor in Finland implicitly assumes a 2\% real growth in wages, resulting in a higher initial benefits than a simple application of the actuarial principles would produce, considering the regular annual pension indexation. This front-loads the payments from the pension system, i.e., pensioners receive a share of the real economic growth in advance, which will not be compensated later by deducting the $2 \%$ increase from the yearly income indexation as legislated, e.g., in Sweden or Norway. This impacts the pension wealth and intergenerational fairness. Conceptually, the Finnish life expectancy coefficient adjusts entry pensions similarly to the annuity conversion factor adopted in NDC schemes.

Second, contrary to Portugal and Finland, who revise the sustainability factor each year, incorporating new mortality data in the computation of life expectancy/annuity measures, with Portugal's period estimates based on a three-year (two consecutive cohorts) observation window and Finland's estimates based on a five-year observation window, Spain opted to update the sustainability factor each year but based on a five-year geometric average of the life expectancy gains computed at the age of 67 , revised every five years. The use of longer observation windows in life table computation reduces the random fluctuations in age-specific mortality rates, particularly in smaller populations, providing a more stable basis from which inference on the likelihood of survival within a specific period can be drawn and pension adjustments are made.

Third, if in Finland and Spain the sustainability factor affected all new pensions, in Portugal, since the 2013 parametric pension reform, the reduction factor only applies to those retiring in advance of the normal (statutory) retirement age. This reduces the long-term efficacy of the sustainability factor in reducing the aggregate old age pension 
expenditure, improving pension adequacy for those retiring at the full pension age. We note, however, that this change in the conceptual nature of the sustainability factor in Portugal, which is now essentially an extra penalty for early retirement, was accompanied by a reform automatically indexing the normal pension age to period life expectancy computed at the age of 65 , with the statutory retirement age increasing with two-thirds of the increase in longevity. From the political economy point of view, this was a way to overcome the opposition of social partners and interest groups to the reform, eliminating the double penalty on early retirement while accommodating the impact of higher longevity on the long-term solvency of the public pension scheme. This double-penalty effect on retirement income introduced by combining sustainability factors with increasing statutory retirement ages was one of the main reasons that determined the suspension (rejection) of the Spanish reform, highlighting that reforming pensions is politically difficult in any country.

Finally, the factor design in Finland and Spain does not recognize the value of long contribution careers, and in the three countries analyzed it does not provide for minimum adequacy safeguards, particularly for those at the lower end of the income (and pension) distribution. In addition, sustainability factors do not provide for heterogeneity in life expectancy and lifespan inequality between socioeconomic groups, genders, and types of work, and for differences between life expectancy and healthy (and disability-free) life expectancy. This reality cannot be ignored and must be covered by supporting social insurance (disability) policy, financed with sources external to the system (e.g., general or dedicated taxes) if necessary.

In recent decades, the three countries have introduced numerous parametric pension reforms, including linking the normal and early retirement ages to life expectancy, increasing the period to calculate the reference wage from the last or best years to a full (or more extended) contribution career, merging the civil servant's scheme with the general private worker's regime, increasing the penalties for early retirement, revising contributory requirements. The role of supplementary pensions in old age income provision has been reinforced in some countries. The focus of pension reforms has been to enhance the fiscal sustainability of pension schemes to prepare for rapid population aging and a declining workforce. Together with tightened eligibility conditions, the impact of sustainability factors on the benefit ratio raises, however, pension adequacy concerns. With lower initial pension levels, safeguarding the long-term adequacy of pensions requires greater attention to social assistance benefits and pension indexation rules, since inadequate indexation erodes the purchasing power of retirement income, increasing old age (absolute and relative) poverty risks. It requires a reassessment of pension taxation schemes towards creating incentives to save for retirement and the use of equity release schemes to extract income from housing wealth [10].

To mitigate the impact of sustainability factors on pension entitlements, the three countries analyzed in this study have incentives for those working longer. We estimate that working lives will have to be extended well beyond normal retirement ages to compensate for the sustainability factor effect on pensions. In 2050, we estimate that retirement ages will have to be postponed between a minimum of 3.714 years in Finland and a maximum of 6.184 years in Portugal to offset pension cuts. The benefit cuts imposed by sustainability factors strongly encourage workers to postpone retirement, closing the positive gap between the normal and the effective retirement age. They also highlight the importance of retirement timing decisions in planning for retirement.

Strengthening the incentives and the capacity of older workers to stay longer in the labor market requires, nevertheless, a coordinated reform agenda in multiple areas. This includes developing and maintaining competencies and skills throughout careers, preparing older workers for the digital transformation of the economy and increasingly disruptive labor markets, strengthening their employability, promoting healthier lifestyles, developing healthy and satisfactory working environments, removing incentives to early retirement, preventing disability and long-term unemployment benefits being used as a pathway to early retirement, promoting phased retirement and/or return-to-work programs to retain 
or to recruit talent at all ages, introducing and/or reinforcing age discrimination legislation and promoting age-inclusive workforce policies, increasing the employers perceptions of the value of experienced workers and generation diversity within firms.

\subsection{Conclusion and Further Research}

This paper examines the policy design and implications of linking entry pensions to life expectancy developments through sustainability factors or life expectancy coefficients in Finland, Portugal, and Spain. Additionally, we contribute to the literature by addressing conceptual and specification uncertainty in policymaking by proposing and applying a Bayesian Model Averaging approach to stochastic mortality modeling and life expectancy computation.

The empirical results obtained in the study have important policy implications on the design of sustainability factors linking entry pensions to life expectancy developments. The results show that sustainability factors will generate substantial pension entitlement reductions in the three countries analyzed, particularly in Portugal where the policy design severely penalizes early retirement and departs from actuarially fair and intergenerationally neutral criteria. In 2050, a Portuguese worker retiring early will receive an initial pension reduced by $27.06 \%$ on top of $0.5 \%$ for each month in advance of the normal retirement age, which is itself increasing with life expectancy developments. This is believed to provide the rational individual financial incentives to postpone retirement, but reality shows that some choose to retire as early as possible even if they have to accept a lower pension, increasing old age poverty risks.

The empirical results also show that the use of a cohort instead of a period approach to life expectancy computation would slightly increase the benefit cuts caused by sustainability factors in countries in which the life expectancy gap is forecasted to increase (Finland, Portugal). In countries in which the life expectancy gap is predicted to remain stable (a.k.a. Spain), the sustainability factor computed using the two alternative longevity measures is similar. Like the reform approaches indexing the retirement age to life expectancy, we conclude that the use of an inappropriate longevity measure compromises the initial policy goals.

The empirical results also show that, for similar longevity increases, the Finnish life expectancy coefficient design mitigates the pension benefit cuts when compared to the policy design adopted in Portugal and Spain. This is because of the discounting (time value of money) effect considered in Finland, which discounts survival probability at a constant $2 \%$ per year.

The BMA composite model developed in this paper tackles conceptual uncertainty concerns in responsible policy decision-making and provides, in our opinion, a sounder basis for statistical inference and a novel prospective approach to policy design under uncertainty. The future of intergenerational social contracts depends on our decisions now. To eliminate surprises and avoid the need for radical welfare state retrenchments in the long term, it is critical to explore in the present alternative policy options to tackle the challenges posed by increasing longevity. Denying uncertainty in social policy, either negating it ("it does not exist"), ignoring it ("acting if it is not there"), or banishing it ("it is not to be dealt with") is denying that it could be otherwise, giving up on trying to find the best solutions to current and future problems. The model combination approach proposed in this paper conveys the message that is preferable to use best-estimate methodologies (based on state-of-the-art scientific knowledge) to produce plausible future scenarios, examining the consequences that would follow from the implementation of alternative policy responses and picking the one that produces the highest welfare for the society.

Some countries have moved one step further by incorporating error-correction mechanisms in their pension systems to accommodate for deviations from best estimates of the key parameters. For instance, in Sweden, the NDC initial pension benefit is computed considering an imputed real rate of return of $1.6 \%$ per year ("the norm") in the annuity factor. Pensions are adjusted annually by the increase in the CPI and the increase in average 
real wages minus the norm. This corrects for deviations between the imputed (forecasted) average real wage increase and the actual growth. Model risk concerns can be further reduced with model management, for instance through testing, validation, audit, governance, and communication policies, together with scientific independent review.

The factor design adopted in the three countries studied uses a uniform period life expectancy estimate for all pensioners. The significant and persistent inequality in the length of life across the members of a population observed in many countries introduces fairness and redistribution concerns in the design and reform of retirement income schemes. Longevity heterogeneity perverts the redistributive objectives of pension schemes and risks invalidating ongoing reform approaches establishing a closer contribution-benefit link and enforcing intra- and intergenerational fairness. This raises questions about the social fairness of public pension schemes, which may ultimately undermine the public support for the intergenerational contract. Adopting non-uniform policy approaches considering the exante life expectancy gradient, e.g., implementing differential retirement ages, sustainability factors, or social contribution rates, are some of the possible reform avenues aiming at reducing the redistributive distortions created by longevity heterogeneity. These are all topics for further research. In the long run, this problem calls for social investments in public health targeting disadvantaged groups in the early stages of life when the long-term gradients in health and income are often determined and crystallized for life.

Further research could investigate the use of alternative stochastic mortality models in the BMA approach, capturing different data features, such as heterogeneity, mortality jumps, and non-linearity, and statistical and methodological considerations, such as the use of cross-validation in estimating weights or selecting the individual mortality forecasting methods, or alternative ensemble learners such as stacked regression ensembles.

The COVID-19 pandemic triggered substantial negative effects on national economies and affected national pension schemes and retirement income providers in a variety of ways. Although public pension schemes have diverse and complex designs, they have been affected, for instance, in the social contribution revenue due to increased unemployment, lower wages, firm liquidation, and temporary tax reductions or exemptions. Pension expenditures were also affected due to the death of numerous pensioners, which terminates their pensions, but create survivor's pensions. The substantial increase in public expenditure to support individuals and companies, the plunge in tax revenues resulting from the sudden economic downturn, and the rise in public debt ratios are likely to have a negative longterm effect on the capacity of governments to finance non-contributory pensions tackling old age poverty. The impact can be minimized if pension reserve funds are used. The pandemic delayed or suspended pension reforms (e.g., France, Spain). Further research is thus needed to investigate whether the catastrophic mortality event has the potential to affect life expectancy permanently and severely at all ages, in an identical or non-uniform way across socioeconomic groups, and how it will impact key pension policy parameters, such as the retirement age and sustainability factors. The magnitude of the long-term direct and indirect implications of the pandemic on life expectancy markers as a consequence of the structural change in the health, economic, financial, and social dimensions of life is still uncertain. The consequences will ultimately be the result of the containment measures adopted to halt the spread of the disease, of the vaccine and therapy solutions developed and adopted, of improved attention to public health care and social inequalities, of changes in people's livelihoods, of the asymmetric digital transformation of the economy and the world of work, of changing lifestyle, living standards and diet habits, of the long-term multiplier effect of economic recovery plans [28].

Finally, most stochastic mortality models considered in the literature assume changes in life expectancy occur gradually and smoothly over many years, the exception being continuous-time affine jump-diffusion models (see, e.g., [22,25]). The pandemic highlighted the importance of modeling human longevity accounting for both negative and positive jumps in mortality rates, possibly of different sizes. Future research could investigate the inclusion of these types of models in the BMA approach. Moreover, differences in the 
age-specific patterns of mortality, population size, and age structure make cross-national comparisons of the impact of the pandemic challenging (see, e.g., [20]).

Author Contributions: Conceptualization, J.M.B. and M.A.; methodology, J.M.B. and M.A.; software, J.M.B. and M.A.; validation, J.M.B. and M.A.; formal analysis, J.M.B. and M.A.; investigation, J.M.B. and M.A.; writing—original draft preparation, J.M.B. and M.A.; writing—review and editing, J.M.B. and M.A. All authors have read and agreed to the published version of the manuscript.

Funding: This research was funded by Portuguese national science funds through FCT under the grant UIDB/04152/2020 —Centro de Investigação em Gestão de Informação (MagIC) (J.M. Bravo), by the Spanish Ministry of Science and Innovation for funding received under grant PID2019-105986GBC21 (M. Ayuso) and by Secretaria d'Universitats i Recerca del departament d'Empresa i Coneixement de la Generalitat de Catalunya for funding received under grant 2020-PANDE-00074.

Institutional Review Board Statement: Not applicable.

Informed Consent Statement: Not applicable.

Data Availability Statement: Not applicable.

Acknowledgments: The authors would like to express their gratitude to the anonymous reviewers for their careful reviews and insightful comments that helped strengthen the quality of the paper.

Conflicts of Interest: The authors declare no conflict of interest.

\section{Appendix A. Stochastic Mortality Models: Technical Description}

This section draws heavily on Bravo et al. [18,49] and recapitulates the key technical details of the individual stochastic mortality models considered in the Bayesian model ensemble approach. It is included here for completeness.

\section{Appendix A.1. GAPC Stochastic Mortality Models}

Generalized age-period-cohort (GAPC) stochastic mortality models belong to a category of parametric models linking a response variable with a linear or bilinear predictor structure. The model structure comprises a random component, a systematic component linking the response variable to a linear predictor $\eta_{x, t}$, comprehending a series of factors related to age $x$, period (calendar year) $t$, and year of birth (or cohort) effects, $c=t-x$, a link function, a set of identifiability constraints, and univariate time series methods for forecasting and simulating the period and cohort indexes [55]. The stochastic component of the model specifies whether death counts $D_{x, t}$ follow a Poisson or a Binomial distribution, i.e., whether $D_{x, t} \sim \mathcal{P}\left(\mu_{x, t} E_{x, t}^{c}\right)$ with $\mathbb{E}\left(D_{x, t} / E_{x, t}^{c}\right)=\mu_{x, t}$ or whether $D_{x, t} \sim \mathcal{B}\left(q_{x, t} E_{x, t}^{0}\right)$ with $\mathbb{E}\left(D_{x, t} / E_{x, t}^{0}\right)=q_{x, t}$, where $E_{x, t}^{0}$ and $E_{x, t}^{c}$ represent the population initially or centrally exposed-to-risk, respectively; $q_{x, t}$ is the one-year probability that individuals of age $x$ in year $t$ will not survive. The linear predictor is defined as:

$$
\eta_{x, t}=\alpha_{x}+\sum_{i=1}^{N} \beta_{x}^{(i)} \kappa_{t}^{(i)}+\beta_{x}^{(0)} \gamma_{t-x}
$$

where $\exp \left(\alpha_{x}\right)$ denotes the historical shape of the mortality schedule across age, $\beta_{x}^{(i)} \kappa_{t}^{(i)}$ is a set of $N$ age-period terms describing the dynamics of mortality over time and age, and $\beta_{x}^{(0)} \gamma_{t-x}$ represents the cohort effects. Maximum-likelihood methods are used to estimate the parameters. To generate forecasts of age-specific mortality rates or probabilities, the period $\kappa_{t}^{(i)}$ and the cohort $\gamma_{t-x}$ indices are treated as stochastic processes and modeled with general univariate $\operatorname{ARIMA}(p, d, q)$ time series methods.

\section{Appendix A.2. Weighted Hyndman-Ullah Method}

The weighted Hyndman-Ullah method [32] combines functional principal component analysis (PCA) with nonparametric penalized regression splines using geometrically de- 
caying weights [56]. Let $\log m_{x_{i}, t} \equiv y_{t}\left(x_{i}\right)$ denote the logarithm of the observed mortality rate at age $x \in\left[x_{1}, x_{p}\right]$ in year $t \in\left[t_{1}, t_{n}\right]$. The model specifies that $y_{t}\left(x_{i}\right)$ is a realization of an underlying continuous and smooth function $f_{t}\left(x_{i}\right)$ and of a noise function $\sigma_{t}\left(x_{i}\right)$ that varies with age, i.e.,

$$
y_{t}\left(x_{i}\right)=f_{t}\left(x_{i}\right)+\sigma_{t}\left(x_{i}\right) \varepsilon_{t, i}, i=1, \ldots, p \quad t=1, \ldots, n,
$$

with

$$
f_{t}(x)=\hat{a}^{*}(x)+\sum_{j=1}^{J} b_{j}^{*}(x) k_{t, j}+e_{t}(x),
$$

where $\sigma_{t}\left(x_{i}\right)$ varies with $x_{i}, \varepsilon_{t, i}$ is an i.i.d. standard normal random variable; $\hat{a}^{*}(x)$ is estimated by:

$$
\hat{a}^{*}(x)=\frac{1}{n} \sum_{j=1}^{J} w_{t} f_{t}(x), \quad \sum_{j=1}^{J} w_{t}=1,
$$

where $w_{t}$ is a set of weights; $\pi \in(0,1)$ is a geometrically decaying weight parameter; $\mathcal{B}^{*}=\left\{b_{j}^{*}(x)\right\}(j=1, \ldots, J)$ is a set of weighted first $J$ functional principal components with uncorrelated scores $\left\{k_{t, j}\right\}$ extracted from the set of weighted curves using a functional PCA; $J<n$ is the number of principal components used; $e_{t}(x)$ is the error function. The method decomposes the smoothed mortality curves $\mathcal{I}=\left\{y_{1}(x), \ldots, y_{n}(x)\right\}$ into orthogonal functional principal components and their corresponding uncorrelated scores.

\section{Appendix A.3. CP-Splines Model}

The CP-Splines model [29] extends the two-dimensional P-splines model [30] by incorporating demographic constraints to ensure that future mortality profiles are biologically plausible over the whole age range. Let $\boldsymbol{Y}=\left(D_{x, t}\right)$ and $\boldsymbol{E}=\left(E_{x, t}\right)$ denote a dataset comprehending deaths and exposure-to-risk, respectively, and assume $Y$ follows a Poisson distribution. The approach fits and forecasts mortality over age and time combining fixed knot B-splines with a two-dimensional smoothing penalty. Let $\boldsymbol{B}_{x}, m \times k_{x}$ and $\boldsymbol{B}_{t}, n \times k_{t}$ represent the B-splines defined over ages and years, respectively; $m$ is the number of ages and $n$ the number of years. The log mortality is described as follows:

$$
\ln [\mathbb{E}(\boldsymbol{Y})]=\ln (\boldsymbol{E})+\boldsymbol{B} \boldsymbol{\alpha}
$$

where $\boldsymbol{\eta}=\boldsymbol{B} \boldsymbol{\alpha}$ is the linear predictor, $\boldsymbol{\alpha}$ are parameters, $\ln (\boldsymbol{E})$ is the offset, and $\boldsymbol{B}=\boldsymbol{B}_{t} \otimes \boldsymbol{B}_{x}$. The smoothing penalty is defined as

$$
\boldsymbol{P}=\lambda_{x}\left(\boldsymbol{I}_{k_{t}} \otimes \boldsymbol{D}_{x}^{\prime} \boldsymbol{D}_{x}\right)+\lambda_{t}\left(\boldsymbol{D}_{t}^{\prime} \boldsymbol{D}_{t} \otimes \boldsymbol{I}_{k_{x}}\right),
$$

where $\lambda_{x}$ and $\lambda_{t}$ are age and time smoothing parameters, respectively; $\boldsymbol{I}_{k_{x}}$ and $\boldsymbol{I}_{k_{t}}$ are identity matrices of size $k_{x}$ and $k_{t}$, respectively; and $\boldsymbol{D}_{x}$ and $\boldsymbol{D}_{t}$ are difference matrices over ages and years of the coefficient matrix. The model is complemented with shape constraints and asymmetric penalties on mortality rate improvements over time $\boldsymbol{D}_{t}^{t}$ and on the speed of aging $\boldsymbol{D}_{x}^{t}$ to guarantee mortality patterns are biologically plausible and consistent over age and time.

\section{Appendix A.4. Regularized SVD Model}

The regularized singular value decomposition (RSVD) model extends one-way functional PCA to two-way functional data by combining both left and right singular vector regularization [31,41]. The RSVD model assumes mortality rates $m(x, t)$ are explained by

$$
m(x, t)=\sum_{j=1}^{q} d_{j} U_{j}(t) V_{j}(x)+\varepsilon(x, t),
$$


where $d_{q}$ is the singular value, $U_{i}(\cdot)$ is a smooth function of time, $V_{j}(\cdot)$ is a smooth function of age, and $\varepsilon(x, t)$ is a zero-mean random noise. The model is fitted sequentially. Let $\boldsymbol{X}=\left(m_{x, t}\right)_{n \times p}$ be a data matrix with $n$ ages and $p$ calendar years. The first pair of singular vectors of $X, U_{1}(t)$ and $V_{1}(x)$ solves the least-squares problem

$$
(\hat{u}, \hat{v})=\underset{(u, v)}{\arg \min }\left\|X-u v^{T}\right\|_{F^{\prime}}^{2}
$$

where $\|\cdot\|_{F}$ is the Euclidean norm of a matrix. Following pairs are obtained successively by detaching the effect of preceding pairs. The RSVD definition of regularized singular vectors for two-way functional data is

$$
(\hat{u}, \hat{\boldsymbol{v}})=\underset{(\boldsymbol{u}, \boldsymbol{v})}{\arg \min }\left\{\left\|\boldsymbol{X}-\boldsymbol{u} \boldsymbol{v}^{T}\right\|_{F}^{2}+\mathcal{P}_{\lambda}(\boldsymbol{u}, \boldsymbol{v})\right\},
$$

where $\mathcal{P}_{\lambda}(\boldsymbol{u}, \boldsymbol{v})$ is a regularization penalty

$$
\mathcal{P}_{\lambda}(u, v)=\lambda_{u} u^{T} \boldsymbol{\Omega}_{u} u \cdot\|v\|^{2}+\lambda_{v} v^{T} \boldsymbol{\Omega}_{v} v \cdot\|u\|^{2}+\lambda_{u} u^{T} \boldsymbol{\Omega}_{u} u \cdot \lambda_{v} v^{T} \boldsymbol{\Omega}_{v} v,
$$

where $\lambda$ is a vector of regularization parameters, and $\boldsymbol{\Omega}_{u}(n \times n)$ and $\boldsymbol{\Omega}_{v}(p \times p)$ are symmetric and non-negative definite penalty matrices. General univariate ARIMA processes are used to model $U_{i}(t)$ and forecast mortality rates.

\section{References}

1. Al-Nator, M.; Al-Nator, S. Accumulative Pension Schemes with Various Decrement Factors. Mathematics 2020, 8, 2081. [CrossRef]

2. OECD. Pensions at a Glance 2019: OECD and G20 Indicators; OECD Publishing: Paris, France, 2019.

3. Bosworth, B.; Weaver, K. Social Security on Auto-Pilot: International Experience with Automatic Stabilizer Mechanisms. Center for Retirement Research at Boston College Working Paper No. 2011-18. 2011. Available online: https:/ /ssrn.com/abstract=1970310 (accessed 30 September 2021).

4. Turner, J. Social Security Financing: Automatic Adjustments to Restore Solvency; AARP Research Report 2009-01. Available online: https:/ /www.aarp.org/work/social-security/info-02-2009/2009_01_socsec.html (accessed on 15 August 2021).

5. Barr, N.; Diamond, P. Reforming pensions: Principles, analytical errors and policy directions. Int. Soc. Secur. Rev. 2009, 62, 5-29. [CrossRef]

6. Ebbinghaus, B. The Privatization and Marketization of Pensions in Europe: A Double Transformation Facing the Crisis. Eur. Policy Anal. 2015, 1, 56-73. [CrossRef]

7. Carrera, L.; Angelaki, M. The Diversity and Causality of Pension Reform Pathways: A Fuzzy-set Qualitative Comparative Analysis. J. Soc. Policy 2020, 49, 582-600. [CrossRef]

8. Bonoli, G.; Palier, B. When past reforms open new opportunities: Comparing old age insurance reforms in Bismarckian welfare systems. Soc. Policy Adm. 2007, 41, 555-573. [CrossRef]

9. Ayuso, M.; Bravo, J.M.; Holzmann, R. Automatic indexation of pension age to life expectancy: When policy design matters. Risks 2021, 9, 96. [CrossRef]

10. Bravo, J.M. Taxation of Pensions in Portugal: A Semi-Dual Income Tax System. CESifo DICE Rep. 2016, 14, 14-23.

11. Bravo, J.M. Funding for longer lives: Retirement wallet and risk-sharing annuities. Ekonomiaz 2019, 96, $268-291$.

12. Bravo, J.M. Longevity-Linked Life Annuities: A Bayesian Model Ensemble Pricing Approach. In Proceedings of the Atas da 20th Conferência da Associação Portuguesa de Sistemas de Informação 2020, Porto, Portugal, 11-12 October 2020; CAPSI 2020 Proceedings. Available online: https:/ / aisel.aisnet.org/capsi2020/29 (accessed on 30 January 2021).

13. Bravo, J.M.; de Freitas, N.E.M. Valuation of longevity-linked life annuities. Insur. Math. Econ. 2018, 78, 212-229. [CrossRef]

14. Olivieri, A. Designing Annuities with Flexibility Opportunities in an Uncertain Mortality Scenario. Risks 2021, 9, 189. [CrossRef]

15. Alho, J.; Bravo, J.M.; Palmer, E. Annuities and life expectancy in NDC. In Nonfinancial Defined Contribution Pension Schemes in a Changing Pension World, Volume 2, Gender, Politics, and Financial Stability; Holzmann, R., Palmer, E., Robalino, D., Eds.; World Bank: Washington, DC, USA, 2013; pp. 395-436.

16. Ayuso, M.; Bravo, J.M.; Holzmann, R. Getting Life Expectancy Estimates Right for Pension Policy: Period versus Cohort Approach. J. Pension Econ. Financ. 2021, 20, 212-231. [CrossRef]

17. Goldstein, J.R.; Wachter, K.W. Relationships between period and cohort life expectancy: Gaps and lags. Popul. Stud. 2006, 60, 257-269. [CrossRef] [PubMed]

18. Bravo, J.M.; Ayuso, M.; Holzmann, R.; Palmer, E. Addressing the life expectancy gap in pension policy. Insur. Math. Econ. 2021, 99, 200-221. [CrossRef]

19. Walker, W.E.; Marchau, V.A. Dealing with Uncertainty in Policy Analysis and Policymaking. Integr. Assess. 2003, 4, 1-4. [CrossRef] 
20. Aburto, J.M.; Villavicencio, F.; Basellini, U.; Kjærgaard, S.;Vaupel, J.W. Dynamics of life expectancy and life span equality. Proc. Natl. Acad. Sci. USA 2020, 117, 5250-5259. [CrossRef] [PubMed]

21. Ayuso, M.; Bravo, J.M.; Holzmann, R. On the heterogeneity in longevity among socioeconomic groups: Scope, trends, and implications for Earnings-Related Pension Schemes. Glob. J. Hum. Soc. Sci.-Econ. 2017, 17, 31-57. [CrossRef]

22. Chetty, R.; Stepner, M.; Abraham, S.; Lin, S.; Scuderi, B.; Turner, N.; Bergeron, A.; Cutler, D. The association between income and life expectancy in the United States, 2001-2014. J. Am. Med. Assoc. 2016, 315, 1750-1766. [CrossRef]

23. van Raalte, A.; Sasson, I.; Martikainen, P. The case for monitoring life-span inequality. Science 2018, 362, 1002-1004. [CrossRef]

24. Atance, D.; Debón, A.; Navarro, E. A Comparison of Forecasting Mortality Models Using Resampling Methods. Mathematics 2020, 8, 1550. [CrossRef]

25. Bravo, J.M.; Nunes, J.P.V. Pricing Longevity Derivatives via Fourier Transforms. Insur. Math. Econ. 2021, 96, 81-97. [CrossRef]

26. Brouhns, N.; Denuit, M.; Vermunt, J.K. A Poisson Log-Bilinear Regression approach to the construction of projected life tables. Insur. Math. Econ. 2002, 31, 373-393. [CrossRef]

27. Cairns, A.J.G.; Blake, D.; Dowd, K.; Coughlan, G.D.; Epstein, D.; Ong, A.; Balevich, I. A quantitative comparison of stochastic mortality models using data from England and Wales and the United States. N. Am. Actuar. J. 2009, 13, 1-35. [CrossRef]

28. Cairns, A.J.G.; Blake, D.; Kessler, A.; Kessler, M. The Impact of COVID-19 on Future Higher-Age Mortality. 2020. Available online: https: / / ssrn.com/abstract=3606988 (accessed on 31 Aug 2021).

29. Camarda, C.G. Smooth constrained mortality forecasting. Demogr. Res. 2019, 41, 1091-1130. [CrossRef]

30. Currie, I. Smoothing and Forecasting Mortality Rates with P-Splines; DP Heriot Watt University: Edinburgh, UK, 2006.

31. Huang, J.Z.; Shen, H.; Buja, A. The analysis of two-way functional data using two-way regularized singular value decompositions. J. Am. Stat. Assoc. 2009, 104, 1609-1620. [CrossRef]

32. Hyndman, R.J.; Ullah, M.S. Robust forecasting of mortality and fertility rates: A functional data approach. Comput. Stat. Data Anal. 2007, 51, 4942-4956. [CrossRef]

33. Hyndman, R.J.; Booth, H.; Yasmeen, F. Coherent mortality forecasting: the product-ratio method with functional time series models. Demography 2013, 50, 261-283. [CrossRef]

34. Jevtić, P.; Regis, L. A continuous-time stochastic model for the mortality surface of multiple populations. Insur. Math. Econ. 2019, 88, 181-195. [CrossRef]

35. Lee, R.D.; Carter, L.R. Modeling and forecasting U.S. mortality. J. Am. Stat. Assoc. 1992, 87, 659-671. [CrossRef]

36. Li, N.; Lee, R. Coherent mortality forecasts for a group of populations: an extension of the Lee-Carter method. Demography 2005, 42, 575-594. [CrossRef]

37. Li, H.; Tan, K.S.; Tuljapurkar, S.; Zhu, W. Gompertz law revisited: Forecasting mortality with a multi-factor exponential model. Insur. Math. Econ. 2021, 99, 268-281. [CrossRef]

38. Pascariu, M.; Basellini, U.; Aburto, J.; Canudas-Romo, V. The Linear Link: Deriving Age-Specific Death Rates from Life Expectancy. Risks 2020, 8, 109. [CrossRef]

39. Plat, R. On stochastic mortality modeling. Insur. Math. Econ. 2009, 45, 393-404. [CrossRef]

40. Renshaw, A.E.; Haberman, S. A cohort-based extension to the Lee-Carter Model for mortality reduction factors. Insur. Math. Econ. 2006, 38, 556-570. [CrossRef]

41. Zhang, L.; Shen, H.; Huang, J.Z. Robust regularized singular value decomposition with application to mortality data. Ann. Appl. Stat. 2013, 7, 1540-1561. [CrossRef]

42. Steel, M.F. Model Averaging and Its Use in Economics. J. Econ. Lit. 2020, 58, 644-719. [CrossRef]

43. Bravo, J.M.; Ayuso, M. Previsões de mortalidade e de esperança de vida mediante combinação Bayesiana de modelos: Uma aplicação à população portuguesa. RISTI-Rev. Iber. Sist. Tecnol. Inf. 2020, E40, 128-144. [CrossRef]

44. Bravo, J.M.; Ayuso, M. Forecasting the retirement age: A Bayesian Model Ensemble Approach. In Trends and Applications in Information Systems and Technologies, WorldCIST 2021. Advances in Intelligent Systems and Computing; Rocha, Á., Adeli, H., Dzemyda, G., Moreira, F., Ramalho Correia, A.M., Eds.; Springer: Cham, Switzerland, 2021; Volume 1365, pp. 123-135. [CrossRef]

45. Kontis, V.; Bennett, J.; Mathers, C.; Li, G.; Foreman, K.; Ezzati, M. Future life expectancy in 35 industrialised countries: projections with a Bayesian model ensemble. Lancet 2017, 389, 1323-1335. [CrossRef]

46. Turek, D.; Fletcher, D. Model-Averaged Wald Confidence Intervals. Comput. Stat. Data Anal. 2012, 56, 2809-2815. [CrossRef]

47. Bravo, J.M. Pricing participating longevity-linked life annuities: A Bayesian Model Ensemble approach. Eur. Actuar. J. 2021. [CrossRef]

48. Bravo, J.M.; Herce, J.A. Career breaks, Broken pensions? Long-run effects of early and late-career unemployment spells on pension entitlements. J. Pension Econ. Financ. 2020, 1-27. [CrossRef]

49. Bravo, J.M.; Ayuso, M.; Holzmann, R.; Palmer, E. Intergenerational actuarial fairness when longevity increases: Amending the retirement age. CESifo Working Paper Series 9408, CESifo. 2021. Available online: https://ideas.repec.org/p/ces/ceswps/_9408. html (accessed 10 Dec 2021).

50. Devesa, E.; Devesa, M.; Dominguez-Fabián, I.; Encinas, B.; Meneu, R. The Sustainability Factor: How Much Do Pension Expenditures Improve in Spain? Risks 2020, 8, 134. [CrossRef]

51. Raftery, A.E.; Gneiting, T.; Balabdaoui, F.; Polakowski, M. Using Bayesian Model Averaging to calibrate forecast ensembles. J. Am. Meteorol. Soc. 2005, 133, 1155-1174. [CrossRef] 
52. Cairns, A.J.G.; Blake, D.; Dowd, K. A two-factor model for stochastic mortality with parameter uncertainty: Theory and calibration. J. Risk Insur. 2006, 73, 687-718. [CrossRef]

53. Denuit, M.; Goderniaux, A.-C. Closing and projecting life tables using log-linear models. Bull. Swiss Assoc. Actuar. 2005, 1, 29-48.

54. Human Mortality Database. University of California, Berkeley (USA). 2021. Available online: www.mortality.org (accessed on 15 August 2020).

55. Hunt, A.; Blake, D. On the structure and classification of mortality models. N. Am. Actuar. J. 2021, 25, S215-S234. [CrossRef]

56. Shang, H.L.; Booth, H.; Hyndman, R.J. Point and interval forecasts of mortality rates and life expectancy: A comparison of ten principal component methods. Demogr. Res. 2011, 25, 173-214. [CrossRef] 